\title{
Understanding Fluoroethylene Carbonate and Vinylene Carbonate Based Electrolytes for Si Anodes in Lithium Ion Batteries with NMR Spectroscopy
}

DOI:

10.1021/jacs.8b03408

\section{Document Version}

Accepted author manuscript

Link to publication record in Manchester Research Explorer

Citation for published version (APA):

Jin, Y., Kneusels, N. J. H., Marbella, L. E., Castillo-Martinez, E., Magusin, P. C. M. M., Weatherup, R. S., Jonsson, E., Liu, T., Paul, S., \& Grey, C. P. (2018). Understanding Fluoroethylene Carbonate and Vinylene Carbonate Based Electrolytes for Si Anodes in Lithium Ion Batteries with NMR Spectroscopy. Journal of the American Chemical Society. https://doi.org/10.1021/jacs.8b03408

Published in:

Journal of the American Chemical Society

\section{Citing this paper}

Please note that where the full-text provided on Manchester Research Explorer is the Author Accepted Manuscript or Proof version this may differ from the final Published version. If citing, it is advised that you check and use the publisher's definitive version.

\section{General rights}

Copyright and moral rights for the publications made accessible in the Research Explorer are retained by the authors and/or other copyright owners and it is a condition of accessing publications that users recognise and abide by the legal requirements associated with these rights.

\section{Takedown policy}

If you believe that this document breaches copyright please refer to the University of Manchester's Takedown Procedures [http://man.ac.uk/04Y6Bo] or contact uml.scholarlycommunications@manchester.ac.uk providing relevant details, so we can investigate your claim.

\section{OPEN ACCESS}




\title{
Understanding Fluoroethylene Carbonate and Vinylene Car- bonate Based Electrolytes for Si Anodes in Lithium Ion Batteries with NMR Spectroscopy
}

\author{
Yanting Jin, ${ }^{\dagger}$ Nis-Julian H. Kneusels, ${ }^{\dagger}$ Lauren E. Marbella,${ }^{\dagger}$ Elizabeth Castillo-Martínez, ${ }^{\dagger}$ Pieter C. M. \\ M. Magusin,${ }^{\dagger}$ Robert S. Weatherup,${ }^{\dagger}$ Erlendur Jónsson, ${ }^{\dagger} \neq$ Tao Liu,${ }^{\dagger}$ Subhradip Paul,${ }^{\S}$ and Clare P. \\ Grey*,†
}

'Department of Chemistry, University of Cambridge, Lensfield Road, Cambridge CB2 1EW, United Kingdom

‡Department of Physics, Chalmers University of Technology, Gothenburg, 41296, Sweden

${ }^{\S}$ DNP MAS NMR Facility, Sir Peter Mansfield Magnetic Resonance Centre, University of Nottingham, Nottingham NG7

2RD, United Kingdom

\begin{abstract}
Fluoroethylene carbonate (FEC) and vinylene carbonate (VC) are widely used as electrolyte additives in lithium ion batteries. Here we analyze the solid electrolyte interphase (SEI) formed on binder-free silicon nanowires (SiNWs) electrodes in pure FEC or VC electrolytes containing $1 \mathrm{M} \mathrm{LiPF}_{6}$ by solid-state nuclear magnetic resonance (ssNMR) with and without dynamic nuclear polarization (DNP) enhancement. We find that the polymeric SEIs formed in pure FEC or VC electrolytes consist mainly of crosslinked polyethylene oxide (PEO) and aliphatic chain functionalities along with additional carbonate and carboxylate species. The formation of branched fragments is further confirmed by ${ }^{13} \mathrm{C}-{ }^{13} \mathrm{C}$ correlation NMR experiments. The presence of cross-linked PEOtype polymers in FEC and VC correlates with good capacity retention and high Coulombic efficiencies of the SiNWs. Using ${ }^{29} \mathrm{Si}$ DNP NMR, we are able to probe the interfacial region between SEI and the Si surface for the first time with NMR spectroscopy. Organosiloxanes are identified to form upon cycling, confirming that some of the organic SEI is covalently bonded to the Si surface. We suggest that both the polymeric structure of the SEI and the nature of its adhesion to the redox-active materials are important for electrochemical performance.
\end{abstract}

\section{INTRODUCTION}

To improve the energy density of next generation rechargeable batteries, it is imperative to investigate materials with higher capacity, and that can expand the operating voltage window of the battery. Silicon is a promising anode for lithium ion batteries (LIBs) possessing high specific capacity $(3579 \mathrm{mAh} / \mathrm{g})$ and low operating voltage $\left(0.1-0.4 \mathrm{~V}\right.$ versus $\left.\mathrm{Li} / \mathrm{Li}^{+}\right) .{ }^{1}$ However, the large volume expansion of $\mathrm{Si}(\sim 300 \%)$ during full lithiation leads to fracturing and rapid capacity fade. One strategy to avoid this problem is to use nano-Si, which can sustain the volume variation without significant pulverization. ${ }^{1}$ Yet, nano-Si has a much larger specific surface area and this leads to more electrolyte decomposition on the Si surface, as conventional carbonate-based electrolytes are unstable below $1.2 \mathrm{~V}$ versus $\mathrm{Li} / \mathrm{Li}^{+}$, the electrolyte being reduced to form a passivating layer known as the solid electrolyte interphase (SEI). ${ }^{2}$ Formation of a stable SEI can help prevent further electrolyte decomposition. While the conventional LP30 electrolyte ( $1 \mathrm{M} \mathrm{LiPF}_{6}$ in ethylene carbonate (EC) and dimethyl carbonate (DMC), 50/50, v/v) forms a stable SEI on graphite anodes used in commercial LIBs, the SEI formed on Si is highly unstable and does not prevent continuous electrolyte break-down. The large volume change that occurs on lithiation of silicon likely causes the SEI on Si to crack; subsequent electrolyte reduction occurs on the fresh exposed Si/lithium silicide surface, which leads to incremental irreversible capacity loss. ${ }^{1,3}$

The organic SEI formed in standard LP30 electrolytes mainly consists of lithium alkyl carbonates ${ }^{4}$ and linear PEO-type polymers ${ }^{5,6}$ or oligomers ${ }^{7}$, the $\left(-\mathrm{OCH}_{2} \mathrm{CH}_{2}\right)_{\mathrm{n}}$ species representing as much as $50 \%$ of the total SEI carbon content on the basis of our ${ }^{13} \mathrm{C}$ NMR studies. ${ }^{5}$ Although lithium ethylene dicarbonate (LEDC) has been suggested as a major SEI in the literature, ${ }^{8,9}$ our previous work on Si anode systems indicated that LEDC is a soluble and transient species in LP30 electrolytes, and so it does not effectively passivate Si surface. ${ }^{10}$ Apart from LEDC, a wide range of other soluble degradation products are also present in the standard LP30 electrolyte after prolonged cycling ${ }^{10}$, 
and their continual formation may contribute to the continuous capacity loss of Si anodes in LP30 electrolytes. The electrodes become clogged with SEI, and the decomposition of EC (and attack of DMC by the EC radicals) which forms soluble products proceeds essentially unabated. ${ }^{5,6,10}$

To date, various strategies have been used to stabilize the SEI on Si. Coating Si with carbon ${ }^{11-15}$ and metal ${ }^{16,17}$ can partially stabilize the Si surface and the use of silicon alloys can decrease the activity of lithiated Si towards electrolyte reduction. ${ }^{18}$ Apart from coatings and alloying, one of the most cost-effective ways to form a stable SEI is to use electrolyte additives that modify the composition and properties of the SEI. ${ }^{19,20}$ Among numerous additives, fluoroethylene carbonate (FEC) and vinylene carbonate (VC) are the two most widely used for both Li- and Naion systems. ${ }^{21-24}$ Both additives are structurally related to EC. FEC is a fluorinated form of EC, whereas VC contains a double bond, the double bond polymerizing during decomposition to form oligomers and insoluble polymers. FEC and VC not only improve the capacity retention ${ }^{24}$ but also enhance the thermal stability of the lithiated $\mathrm{Si}$ anode. ${ }^{25}$

A variety of techniques have been used to probe the SEI formed in the presence of FEC and VC on both graphite and high capacity Si electrodes in LIBs. ${ }^{26}$ The organic SEI derived from VC was characterized by Ota et al., who used solution NMR spectroscopy and gas chromatography to prove that poly(VC)-type species were formed on graphite cycled in pure $\mathrm{VC}$ electrolyte. ${ }^{27}$ The formation of poly(VC) has been confirmed by Ouatani et al., who directly synthesized poly(VC) via radical polymerization and compared the XPS valence spectra of synthetic poly(VC) with the SEI formed on graphite. ${ }^{28}$ Moving from graphite to $\mathrm{Si}$, the addition of $\mathrm{VC}$ also enhances the electrochemical performance for $\mathrm{Si}$, and its beneficial effect is generally attributed to the polymeric species that are formed. ${ }^{29}$ Nakai et al. studied the SEI formed on a Si thin film in a FECbased electrolyte without EC. ${ }^{30}$ They found evidence for organic polymers with low oxygen content (e.g., a polyene-type polymer) by using a combination of X-ray photoelectron spectroscopy (XPS) and time-of-flight secondary ion mass spectrometry (ToF-SIMS). ${ }^{30}$ According to the authors, these oxygen deficient polymers prevent the oxidation of the Si surface, and thus, can preserve the active Si material during battery cycling. Conversely, Schroder et al. argued that while oxidation processes are unlikely to occur in the reducing environment on the anode of the battery, the reduction of FEC leads to the formation of a kinetically stable SEI consisting of a denser layer of $\mathrm{LiF}$ and $\mathrm{Li}_{2} \mathrm{O}$ that prevents further electrolyte decomposition. ${ }^{31}$

Our previous study clearly showed that FEC reacts to form VC and vinxoyl species, both being observed via solution NMR in the electrolyte. ${ }^{10}$ No lithium vinylene dicarbonate $\left(\mathrm{Li}_{2} \mathrm{VDC}\right)$ was, however, observed..$^{10}$ An insoluble cross-linked PEO-type polymer is also formed from EC and FEC reactions, with fewer EC degradation products being found in the electrolyte in the presence of FEC than with EC/DMC alone. This cross-linked polymer results from reactions involving $\mathrm{VC}$, vinxoyl radicals and $\mathrm{EC} / \mathrm{DMC}$ and is correlated with improved electrochemical performance.

The nature of the interactions between the SEI species and the Si surface are critical for the stability of the SEI. However, the surface structures of cycled Si remain elusive due to the inherent difficulty in characterizing the buried interphase. Despite these difficulties, XPS studies have reported that, in the cycled Si electrode, the $\mathrm{Si} 2 \mathrm{p}$ peak corresponding to $\mathrm{SiO}_{2}$ shifts to a lower binding energy, indicating that $\mathrm{SiO}_{2}$ may be reduced due to alloying with $\mathrm{Li}$ or the formation of a $\mathrm{Si}-\mathrm{C}$ species. ${ }^{32-34} \mathrm{How}-$ ever, detailed information concerning the nature of the chemical species and structure of the cycled Si surface is still lacking. ${ }^{29} \mathrm{Si}$ NMR is a powerful tool for analyzing Si-containing species, because the various mono- (M), di- (D), tri- (T), and quaternary(Q) substituted siloxanes $\left(\mathrm{Si}(\mathrm{OR})_{\mathrm{n}}\left(\mathrm{R}^{\prime}\right)_{(4-\mathrm{n})}\right.$ with $\mathrm{R}$ denoting $\mathrm{Si}$, $\mathrm{C}$, or $\mathrm{H}$ and $\mathrm{R}$ ' denoting an alkyl moiety) all resonate in distinct chemical shift ranges. Furthermore, a more detailed ${ }^{29} \mathrm{Si}$ NMR analysis can even yield a picture of the second coordination sphere around the $\mathrm{Si}$ atoms, again based on the chemical shift. However, ${ }^{29} \mathrm{Si}$ NMR is not routinely used to probe cycled $\mathrm{Si}$ electrodes due to ${ }^{29} \mathrm{Si}$ 's unfavorable NMR properties (e.g. low natural abundance $(4.7 \%)$, low gyromagnetic ratio, and long $T_{1}$ relaxation times), which generally result in prohibitively long experimental time. To overcome these barriers, we leveraged the signal enhancement from both dynamic nuclear polarization (DNP) from electrons and cross-polarization (CP) from protons ${ }^{35-37}$ to monitor structural changes in the Si surface following cycling vs. Li.

In this study, we characterize both the SEIs derived from $1 \mathrm{M}$ $\mathrm{LiPF}_{6}$ dissolved in pure FEC or VC electrolytes by conventional and DNP magic angle spinning (MAS) solid state NMR (ssNMR) spectroscopy. Pure FEC and VC electrolytes are used to examine their individual effect on $\mathrm{Si}$ anodes; they are also used as model systems to study the decomposition of FEC and VC. Binder-free silicon nanowires (SiNWs) are used to avoid interference from polymer binder in subsequent analyses and to ensure that good electrical connection with the current collector is maintained for multiple cycles (i.e., avoiding dead Si that becomes electrically disconnected during cycling). The chemical structures of the organic SEI formed in FEC and VC are correlated to their electrochemical performances. We show that heterogeneous polymers are formed during the reduction of FEC and VC, which consist of cross-linked PEO-type polymers and aliphatic chains. The presence of highly cross-linked PEO-type polymers correlates with good capacity retention.

\section{EXPERIMENTAL METHODS}

Coin cells: SiNWs were grown by chemical vapor deposition (CVD) as described previously. ${ }^{38}{ }^{13} \mathrm{C}_{3}$-labeled $\mathrm{FEC}$ was synthesized by using a previously reported procedure ${ }^{10} \mathrm{Li}$ half-cells were then assembled with the SiNWs electrodes in 2032-type coin cells, using the freshly prepared electrolytes listed in Table 1. LP30 electrolyte, FEC and VC solvents were purchased from Sigma Aldrich. Borosilicate glass fiber (Whatman, dried under vacuum oven) and was used as the separator and around 10 drops $(\sim 0.15 \mathrm{~mL})$ of electrolyte were used for each cell. Coin cell assembly was carried out in an Ar filled glovebox $\left(\mathrm{H}_{2} \mathrm{O}<0.1 \mathrm{ppm}, \mathrm{O}_{2}<0.1 \mathrm{ppm}\right)$. The coin cells were discharged/charged at room temperature at a constant current $(\mathrm{C} / 30,120$ $\mathrm{mA} / \mathrm{g}$ ) between $0.001 \mathrm{~V}-2 \mathrm{~V}$ vs $\mathrm{Li} / \mathrm{Li}^{+}$for the first cycle using a Biologic VSP, MPG-2 or Lanhe (Wuhan, China) battery test systems. After the first cycle, the coin cells were then cycled at $\mathrm{C} / 10(360 \mathrm{~mA} / \mathrm{g})$ for up to 50 cycles (taking approximately 30 days). After cycling, the cells were disassembled in the glovebox and the SiNW electrodes were dried under vacuum overnight ( $16-20 \mathrm{~h})$ to remove excess electrolyte solvents without rinsing.

Table 1. Electrolyte formulations with $1 \mathrm{M} \mathrm{LiPF}_{6}$ in different solvent mixtures

\begin{tabular}{ll}
\hline Electrolyte solvents & Abbreviation \\
\hline $\mathrm{EC} / \mathrm{DMC}=50 / 50(\mathrm{v} / \mathrm{v})$ & LP30 \\
\hline
\end{tabular}




\begin{tabular}{ll}
\hline $\mathrm{EC} / \mathrm{DMC} / \mathrm{FEC}=45 / 45 / 10(\mathrm{v} / \mathrm{v} / \mathrm{v})$ & $\mathrm{LP} 30+\mathrm{FEC}$ \\
\hline $\mathrm{FEC}$ (fluoroethylene carbonate) & $\mathrm{FEC}$ \\
\hline $\mathrm{VC}($ vinylene carbonate) & $\mathrm{VC}$ \\
\hline $\mathrm{FEC} /{ }^{13} \mathrm{C}_{3} \mathrm{FEC}=95 / 5(\mathrm{v} / \mathrm{v})$ & ${ }^{13} \mathrm{C}_{3} \mathrm{FEC}$ \\
\hline
\end{tabular}

Solid-state NMR measurements $\left({ }^{1} \mathrm{H},{ }^{13} \mathrm{C}\right)$ were performed at $11.7 \mathrm{~T}$ with a Bruker Avance III spectrometer equipped with a $2.5 \mathrm{~mm}$ probehead at a MAS speed of $30 \mathrm{kHz}$ for ${ }^{1} \mathrm{H}$ NMR spectra and $10 \mathrm{kHz}$ for ${ }^{1} \mathrm{H}-{ }^{13} \mathrm{C}$ CP NMR spectra. The $\pi / 2$ pulse lengths were $2.7 \mu$ s for ${ }^{1} \mathrm{H}$. The chemical shifts of ${ }^{1} \mathrm{H},{ }^{13} \mathrm{C}$ were referenced with adamantane $\left({ }^{1} \mathrm{H}\right.$ at 1.87 and ${ }^{13} \mathrm{C}$ at $\left.38.6 \mathrm{ppm}\right)$. Between 64-256 transients
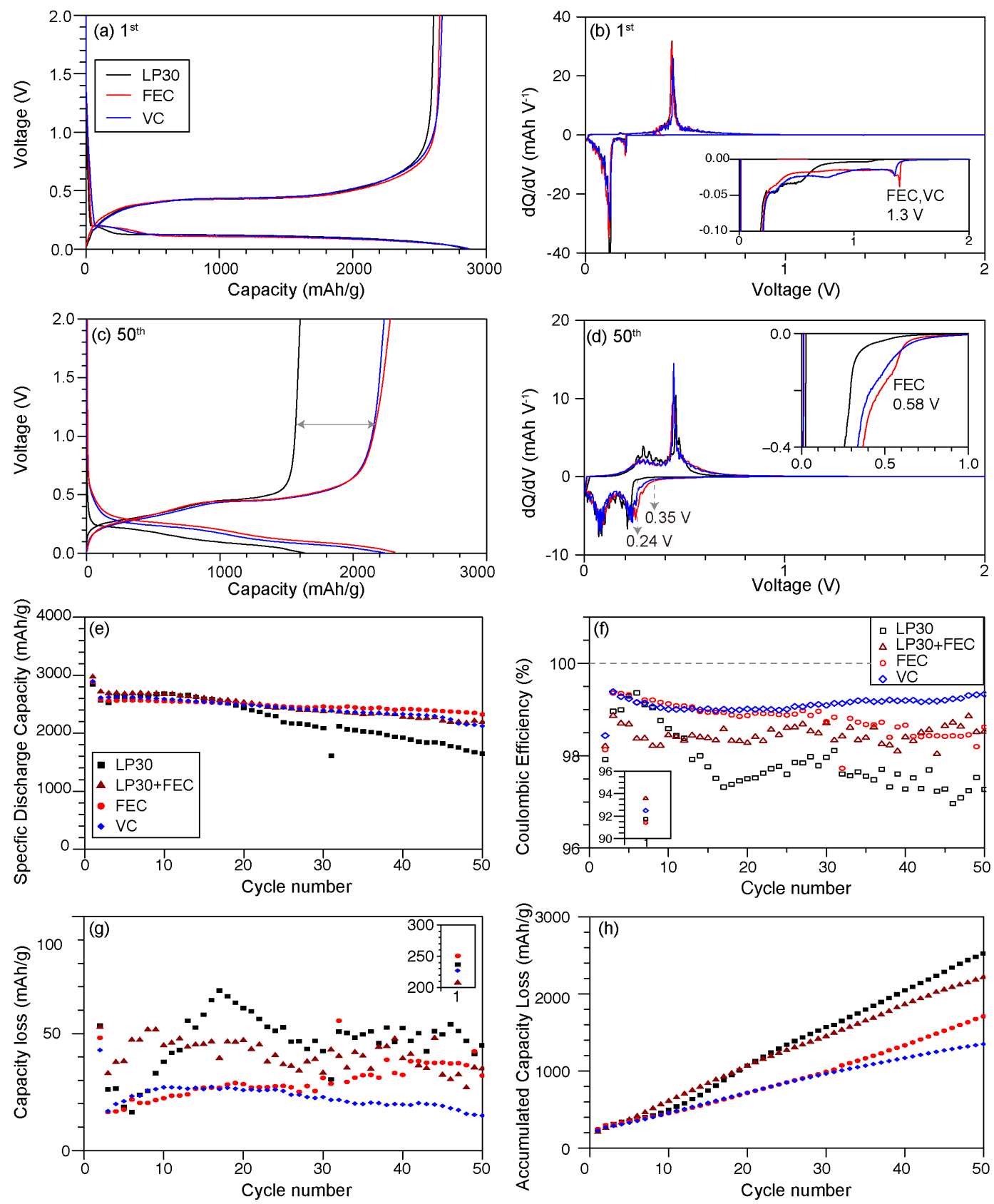

Figure 1 Representative electrochemistry of SiNWs cycled in standard LP30, LP30 + 10 vol \% FEC, and 1 M LiPF 6 in FEC or VC, electrolytes (colored in black, dark red, red and blue, respectively. The voltage profiles and the dQ/dV curves of the SiNWs at the $1^{\text {st }}$ cycle (a-b) and the $50^{\text {th }}$ cycle (c-d) for LP30, FEC and VC. Discharge/lithiation capacity versus cycle number (e) and the corresponding Coulombic efficiency (CE) during cycling (f) for all four electrolytes. The initial CE is shown in the insert in (f). Capacity loss (defined as the lithiation capacity minus the delithiation capacity) during each cycle $(\mathrm{g})$ and accumulated capacity loss versus cycle number (h). The capacity loss of the $1^{\text {st }}$ cycle is shown in the insert in $(\mathrm{g})$. The legend in $(\mathrm{g}-\mathrm{h})$ is the same as in (e). Cells were cycled at $\mathrm{C} / 30$ for the $1^{\text {st }}$ cycle, then at $\mathrm{C} / 10$ for later cycles between $0.001 \mathrm{~V}-2 \mathrm{~V}$.

were collected using recycle delays of $15 \mathrm{~s}$ for ${ }^{1} \mathrm{H}$ experiments. ${ }^{1} \mathrm{H}-{ }^{13} \mathrm{C}$ CP NMR spectra were acquired with a CP contact time of $2 \mathrm{~ms}$, a recycle delay of $3 \mathrm{~s}$ and $21 \mathrm{k}-28 \mathrm{k}$ scans. RF nutation frequencies were $\left({ }^{1} \mathrm{H}\right) 92.5 \mathrm{kHz}(50-100 \%$ linearly ramped during $\mathrm{CP}),\left({ }^{13} \mathrm{C}\right) 82.5 \mathrm{kHz}$, and SPINAL64 ${ }^{39}\left({ }^{1} \mathrm{H}\right)$ decoupling at $80 \mathrm{kHz} .{ }^{13} \mathrm{C}$ direct excitation of 
${ }^{13} \mathrm{C}_{3}$ FEC 100 sample was measured with recycle delay of $60 \mathrm{~s}$ and 5648 scans over the duration of 102.5 hours.

DNP NMR experiments were performed on a 14.1 T Bruker Avance III HD spectrometer with a $395 \mathrm{GHz}$ gyrotron microwave source and using a $3.2 \mathrm{~mm}$ triple resonance wide-bore probe at the Nottingham DNP MAS NMR Facility. The sample transfer and preparation procedure have been described before, ${ }^{10}$ with the exception that a radical solution of $16 \mathrm{mM}$ TEKPol dissolved in 1,1,2,2-tetrachloroethane (TCE) instead of dichlorobenzene was used to achieve better signal enhancement. The sample mass, dilution ratio of $\mathrm{KBr}$ and the volume of radical solutions are listed in Table $\mathrm{S} 1$.

${ }^{1} \mathrm{H}-{ }^{13} \mathrm{C} \mathrm{CP}$ and ${ }^{1} \mathrm{H}_{-}{ }^{29} \mathrm{Si} \mathrm{CP}$ DNP NMR spectra were acquired with a $90-100 \%$ ramped contact pulse ${ }^{40}$ on the ${ }^{1} \mathrm{H}$ channel and $100 \mathrm{kHz}{ }^{1} \mathrm{H}$ decoupling using swept frequency two pulse phase modulation $\left(\mathrm{SW}_{f}\right.$ TPPM $)^{41}$ sequence with MAS frequency of $12.5 \mathrm{kHz}$. The relaxation delay was 3-4 s, and the CP contact time $2 \mathrm{~ms}$ for ${ }^{13} \mathrm{C}$ and $5 \mathrm{~ms}$ for ${ }^{29} \mathrm{Si}$. ${ }^{29} \mathrm{Si}$ DNP direct excitation spectrum was acquired using high powder proton decoupling with a recycle delay of $10 \mathrm{~s}$ and 3072 scans at a spinning speed of $12.5 \mathrm{kHz}$.

Double quantum (DQ) - single quantum (SQ) ${ }^{13} \mathrm{C}-{ }^{13} \mathrm{C}$ dipolar correlation spectra were acquired using POST-C $7^{42}$ for DQ excitation and reconversion at a MAS rate of $8 \mathrm{kHz}$. Proton decoupling was achieved by a $\mathrm{SW}_{f}$-TPPM sequence with $100 \mathrm{kHz}$ RF amplitude on the ${ }^{1} \mathrm{H}$ channel. 256 transients were recorded for each of 128 complex points interleaved, by using a $2 \mathrm{~s}$ of recycle delay for the recovery of ${ }^{1} \mathrm{H}$ magnetization.

${ }^{1} \mathrm{H}-{ }^{29} \mathrm{Si}$ HETCOR spectra were measured using $5 \mathrm{~ms}$ contact time, continuous wave Lee Goldberg (CWLG) proton decoupling, 2048 scans per slice with 32 increments and a recycle delay of $3 \mathrm{~s}$ with MAS frequency of $12.5 \mathrm{kHz}$.

\section{RESULTS:}

\section{Electrochemistry}

The electrochemical performance of SiNWs cycled in Li halfcells using the electrolytes listed in Table 1 are shown in Figure 1. The features in the first discharge/charge curves of the SiNWs in Figure 1a are similar to one another, indicating that pure FEC and pure VC based electrolytes do not affect the $\mathrm{Si}$ lithiation and delithiaton mechanisms. However, the corresponding dQ/dV plot in Figure $1 \mathrm{~b}$ reveals that FEC and VC are preferentially decomposed as early as $1.3 \mathrm{~V} \mathrm{vs.} \mathrm{Li} / \mathrm{Li}^{+}$, whereas LP30 electrolyte decomposition starts around $0.8 \mathrm{~V}$. The process at around $0.2 \mathrm{~V}$ is due to the lithiation of gold, which is used as a catalyst for SiNWs growth. In the $50^{\text {th }}$ cycle (Figure 1c), both the pure FEC and VC samples maintain similar voltage curves with the characteristic $\mathrm{Si}$ de/lithiation plateaus. However, the voltage profile of the LP30 sample shows a lower lithiation voltage $\left(0.24 \mathrm{~V}\right.$ vs. $\left.\mathrm{Li} / \mathrm{Li}^{+}\right)$than the SiNWs cycled in pure FEC and VC electrolytes $(\sim 0.35 \mathrm{~V})$, with the lower lithiation voltage reflecting an increase in resistance, which may come from the reduced porosity of the electrodes and a thicker SEI. ${ }^{6}$ The delithiation voltage curves are similar for all three samples in the $0-0.42 \mathrm{~V}$ range, but after this point they begin to diverge, as manifested in a change in the peak intensity around $0.42-0.70 \mathrm{~V}$ in the $\mathrm{dQ} / \mathrm{dV}$ plots (Figure $1 \mathrm{~d}$ ). A lower delithiation capacity is obtained in the LP30 sample after 50 cycles than with pure FEC and VC electrolytes in this voltage range, as seen in Figure 1c; this may again be related to the transport properties and resistance of the SEI as suggested by the work of Michan et al. ${ }^{6}$, which showed that most of the capacity could be regained when the cells containing LP30 only were cycled at extremely low rates.

In general, SiNWs cycled with FEC or VC-containing electrolytes show improved capacity retention when compared to standard LP30 electrolytes without any additives (Figure 1e). After 50 cycles, the LP30 sample retains only $58 \%$ of the initial capacity; whereas, cells cycled with FEC or VC based electrolytes retain $73-81 \%$ of their initial capacities (see Table S2 in SI for details). The Coulombic efficiencies (CE) (defined as the delithiation capacity versus lithiation capacity) of SiNWs cycled in FEC- and VC- containing electrolytes show noticeable differences (Figure 1f). SiNWs cycled with pure VC show the highest average $\mathrm{CE}$ of $99.1 \%$ from the $2^{\text {rd }}$ to the $50^{\text {th }}$ cycle. FECcontaining samples exhibit a slightly lower average CE of $98.8 \%$ with pure FEC and $98.4 \%$ for LP30 + FEC sample. Yet, both FEC-containing samples are higher than the standard LP30 sample (97.8\%). The CE provides a measure of the irreversible reactions that occur during each cycle (e.g. $\mathrm{Li}^{+}$and/or solvent consumption), the higher the $\mathrm{CE}$, the more reversible the reaction is. The CEs of FEC and VC samples, while noticeably improved over those in LP30 electrolytes, are still less than $99.5 \%$. Cycling data for multiple cells are presented in the SI (Figure S14); while small variations are observed, which are largely ascribed to variations in the SiNW electrodes and errors associated with determining their mass, they are all consistent with the conclusions that pure FEC and VC electrolytes outperform the LP30 based electrolyte. Moreover, the capacity loss of FEC and $\mathrm{VC}$ samples during each cycle and their accumulated capacity losses across multiple cycles are all smaller than LP30 samples (Figure $1 \mathrm{~g}$ and $\mathrm{h}$ ).

${ }^{13} \mathrm{C}_{3}$ labelled $\mathrm{FEC}$ was synthesized and prepared as an electrolyte $\left(1 \mathrm{M} \mathrm{LiPF}{ }_{6}\right.$ in $\left.\mathrm{FEC} /{ }^{13} \mathrm{C}_{3} \mathrm{FEC}\right)$ for cycling with SiNWs and for further NMR studies. The electrochemical performance of the ${ }^{13} \mathrm{C}_{3}$ FEC electrolyte is shown in Figure $\mathrm{S} 13$ and it exhibits similar capacity retention to the ${ }^{13} \mathrm{C}$ natural abundance $\mathrm{FEC}$ and LP30+FEC samples. These electrochemical results suggest that the cells containing the ${ }^{13} \mathrm{C}_{3}$ FEC synthesized as part of this study are representative of cells cycled in pure (non-enriched) FEC electrolytes.

Electrochemical impedance spectroscopy data (Figure S1) and rate performance data (Figure S2) were collected for the SiNWs cycled in FEC, VC and LP30 electrolytes and suggest that the SEI formed in FEC has a higher $\mathrm{Li}^{+}$conductivity than those formed in LP30 electrolyte. Further chemical analysis was then carried out to understand the observed electrochemical differences.

\section{Organic SEI components revealed by ${ }^{1} H$ and ${ }^{13} C$ sSNMR}

Figure 2 shows the ${ }^{1} \mathrm{H}$ and ${ }^{1} \mathrm{H}-{ }^{13} \mathrm{C} C \mathrm{CP}$ NMR spectra of SiNWs cycled in all the electrolyte formulations after the first, 30 and 50 cycles in the delithiated state. The results and assignments for the LP30 and LP30 + FEC system have been discussed in detail previously ${ }^{10}$, but are included here to facilitate comparison with the pure FEC and VC systems. For SiNWs cycled in the standard LP30 electrolyte with and without 10 vol\% FEC (Figure 2a and 2d), the organic SEI mainly consists of PEOtype polymeric species $\left(-\mathrm{CH}_{2} \underline{C H}_{2} \mathrm{O}-\right)$ as indicated by both the prominent ${ }^{1} \mathrm{H}$ and ${ }^{13} \mathrm{C}$ resonances at $4.7 \mathrm{ppm}$ and $70 \mathrm{ppm}$, respectively. ${ }^{5,6}$ On adding $10 \mathrm{vol} \% \mathrm{FEC}$, an extra ${ }^{13} \mathrm{C}$ resonance at approximately $103 \mathrm{ppm}$ is seen (Figure 2d), which is assigned to a cross-linking acetal carbon ( $\left.\mathrm{R} \underline{\boldsymbol{C}} \mathrm{H}\left(\mathrm{OR}^{\prime}\right)_{2}\right)$ moiety. ${ }^{10}$

Similar to the LP30 + FEC sample, ${ }^{13} \mathrm{C}$ NMR spectra of SiNWs cycled in pure FEC and VC (Figures $2 \mathrm{e}$ and $2 \mathrm{f}$ ) also contain acetal carbons (100-108 ppm) and ethylene oxide carbons (70-77 ppm), consistent with the presence of cross-linked 
PEO-type polymers and the formation of poly(VC)-like polymers. However, although both FEC and VC induced SEIs show a beneficial effect in terms of the capacity retention of the $\mathrm{Si}$ electrode, the chemical compositions of FEC-and VC-derived polymers are not identical.

The acetal carbons in VC and FEC samples have ${ }^{13} \mathrm{C}$ chemical shifts at 108 and 103 ppm, respectively. Based on the prior study by Leifer and coworkers ${ }^{43}$, the chemical shift is influenced by the R group in the acetal carbon, the 108 ppm VC resonance being tentatively attributed to an acetal carbon connected to a cyclic R group, potentially in a poly(VC) type crosslinking species ${ }^{44}$; the 103 ppm component of the broader peak in the FEC sample is likely an acetal carbon bound to linear R groups, with the FEC samples also containing the higher frequency peak but in smaller proportions. These assignments is validated by DFT NMR shift calculations, which were performed to explore the effect of different functional groups on the carbon shifts (Figure S15 in the SI). We note that small differences in chemical shifts will also likely result from differences in the nearby chemical species and from different polymer conformations.

The presence of poly(VC) in the VC samples is supported by the ${ }^{1} \mathrm{H}$ and ${ }^{13} \mathrm{C}$ NMR of the ethylene oxide region: the most intense ${ }^{13} \mathrm{C}$ peak of the pure $\mathrm{VC}$ sample (77 ppm) is $7 \mathrm{ppm}$ higher in frequency than that of the FEC sample (Figures 2e and 2f) indicating a more strained polymer (e.g. poly $(\mathrm{VC})^{44,45}$ ) is present. The ${ }^{1} \mathrm{H}$ NMR shows a similar trend: the main broad peak is at around $5.1 \mathrm{ppm}$ for pure VC samples (Figure 2c), yet the primary ${ }^{1} \mathrm{H}$ resonance is observed at approximately $3.8 \mathrm{ppm}$ for FEC samples (Figure 2b). The broad $5.1 \mathrm{ppm}$ peak is assigned to a proton on branched ethylene oxide (-Cㅡㅇ-) in poly(VC), consistent with the solution NMR result report by Ota et al. ${ }^{27}$ Note that the broad peak in ${ }^{1} \mathrm{H}$ NMR at around $5.1 \mathrm{ppm}$ in the $\mathrm{VC}$ sample can also arise from vinylic protons
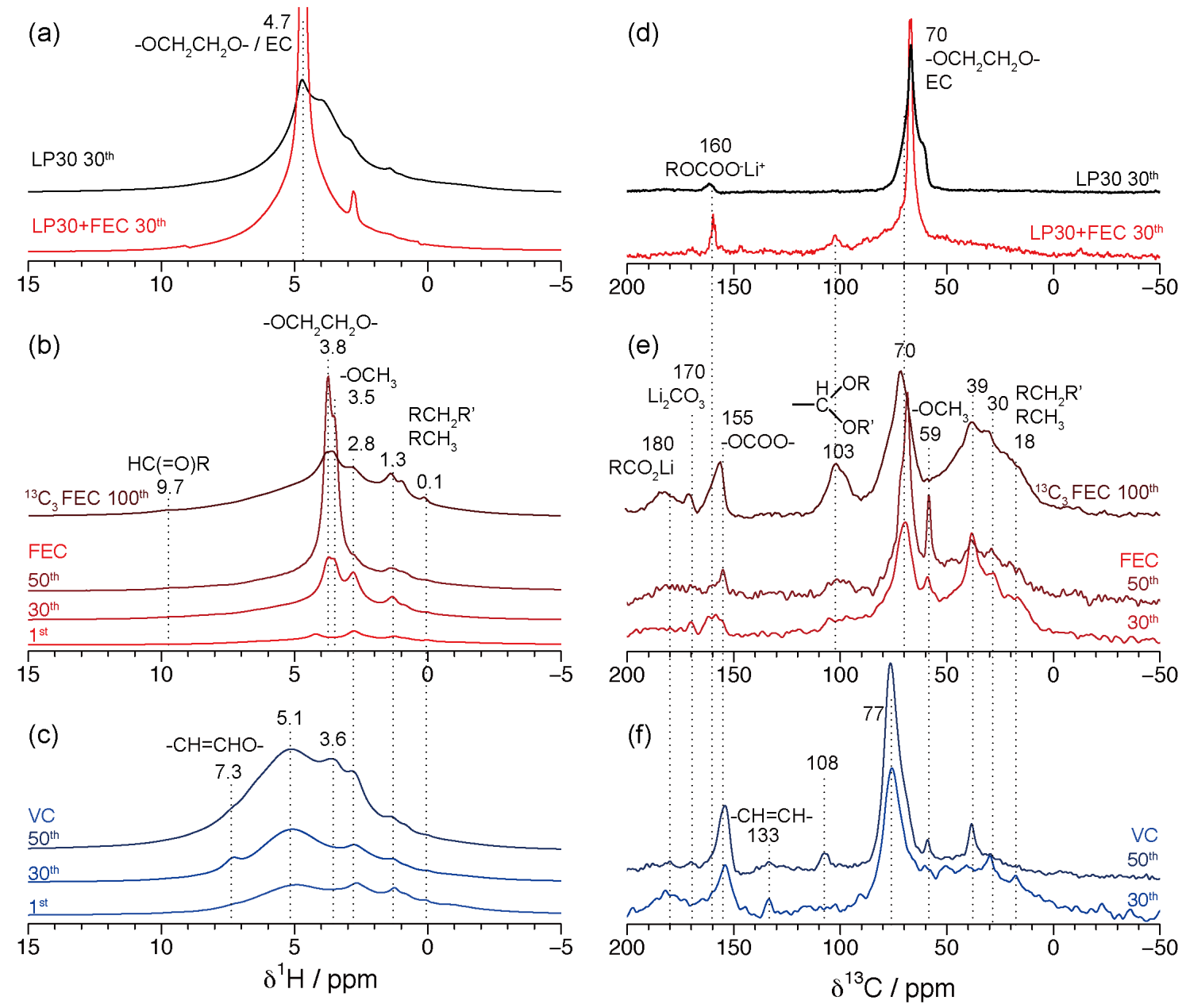

Figure $2{ }^{1} \mathrm{H}$ MAS NMR spectra (a-c) and ${ }^{1} \mathrm{H}-{ }^{13} \mathrm{C}$ CP MAS NMR spectra (d-f) of SiNWs cycled in LP30, LP30 + 10 vol\% FEC, pure FEC and VC electrolytes for the $1^{\text {st }}, 30^{\text {th }}$ and $50^{\text {th }}$ cycle. Spectra of SiNWs cycled in $95 \%$ natural abundance FEC +5 vol $\%{ }^{13} \mathrm{C}_{3} \mathrm{FEC}$ for 100 cycles are included in $(\mathrm{b}, \mathrm{e})$. All spectra were measured at room temperature using conventional ssNMR.

$\left(\underline{\boldsymbol{H}} \mathrm{CR}=\mathrm{CR}_{2}\right)$, but such an alkene carbon is only present in small amounts in the ${ }^{13} \mathrm{C}$ NMR spectra.

In contrast to the LP30-containing systems, SEIs produced from pure FEC or VC contain a higher concentration of aliphatic species, as indicated by the ${ }^{13} \mathrm{C}$ resonances between 0
$40 \mathrm{ppm}$ (Figures 2e and 2f). Aliphatic carbons can be formed by reducing FEC and $\mathrm{VC}$, with the release of $\mathrm{CO}_{2}$ gas (see discussion for more details) and involving reactions of more than one FEC/VC molecule. Methoxide groups $\left(\mathrm{RO} \underline{\boldsymbol{C H}}_{3}\right)$ are also seen for all the FEC and VC samples, which are manifested as 
a ${ }^{1} \mathrm{H}$ peak at 3.5 ppm and a sharp ${ }^{13} \mathrm{C}$ peak at $59 \mathrm{ppm}$, and are correlated to one another in the ${ }^{1} \mathrm{H}-{ }^{13} \mathrm{C}$ heteronuclear correlation (HETCOR) spectrum (Figure S8). The assignment is further supported by the narrow peak width of the $59 \mathrm{ppm}{ }^{13} \mathrm{C} \mathrm{NMR}$ resonance, where the relatively sharp peak can be explained by motional averaging due to fast rotation of the methoxide group.

In order to improve the signal to noise ratio in the ${ }^{13} \mathrm{C} N \mathrm{NM}$ spectra of ${ }^{13} \mathrm{C}$ natural abundance samples, DNP NMR was used to compare the SEIs formed in LP30, FEC, and VC electrolytes after 50 cycles (Figure $3 \mathrm{a}$ ). With a signal enhancement of around 15 for each sample, ${ }^{1} \mathrm{H}-{ }^{13} \mathrm{C} \mathrm{CP}$ DNP NMR reveals the finer details concerning the polymeric species in the 100$200 \mathrm{ppm}$ region. Figure $3 \mathrm{a}$ shows that $\mathrm{sp}^{2}$-hydridized carbon species $(-\mathrm{CH}=\mathrm{CH}-)$ with ${ }^{13} \mathrm{C}$ resonances in the range of 120 $140 \mathrm{ppm}$ are present in both FEC and VC samples (shaded in grey), but not in the LP30 sample. SiNWs cycled in FEC contain additional aldehyde carbons $(\mathrm{H} \underline{\boldsymbol{C}}(=\mathrm{O}) \mathrm{R})$ with a ${ }^{13} \mathrm{C}$ resonance at $210 \mathrm{ppm}$. Lithium carboxylate species $\left(\mathrm{R} \underline{C} \mathrm{OOO}^{-} \mathrm{Li}^{+}\right)$ with a ${ }^{13} \mathrm{C}$ resonance around $180 \mathrm{ppm}$ are also more pronounced in the FEC sample. Both FEC and VC samples contain an intense ${ }^{13} \mathrm{C}$ NMR peak at $155 \mathrm{ppm}$ and a weak signal at $170 \mathrm{ppm}$ that can be assigned to alkyl carbonate (ROCOOR') and $\mathrm{Li}_{2} \mathrm{CO}_{3}$, respectively. ${ }^{46}$ For the LP30 sample, the intense ${ }^{13} \mathrm{C}$ peak at $160 \mathrm{ppm}$ is assigned to lithium alkyl carbonate $\left(\mathrm{ROCOO}^{-} \mathrm{Li}^{+}\right)$, likely from the terminal carbonate species found in linear oligomers or polymer chains. ${ }^{5}$ In short, ${ }^{13} \mathrm{C}$ DNP NMR shows that, apart from the cross-linked PEO polymer, the organic SEIs derived from FEC and VC also contain lithium/alkyl carbonates and additional small amounts of unsaturated carbons.
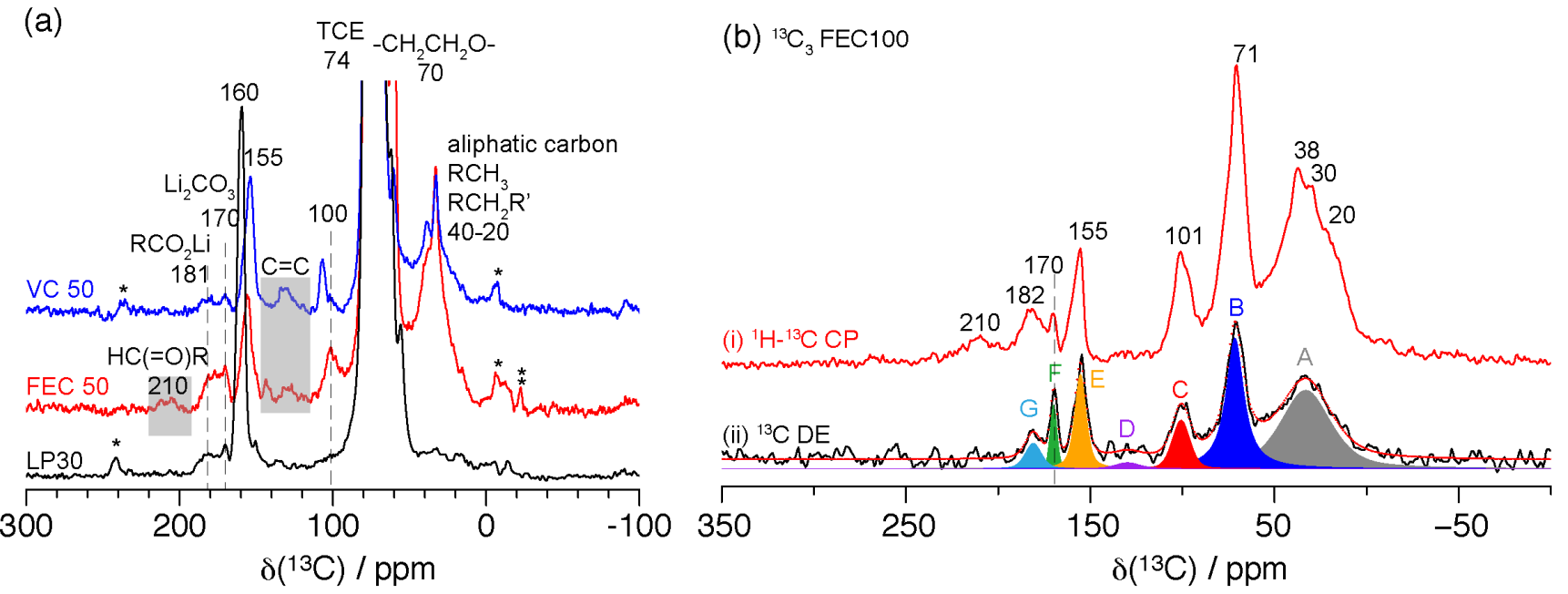

Figure 3 (a) ${ }^{1} \mathrm{H}_{-}{ }^{13} \mathrm{C}$ CP DNP NMR (105 K) spectra of SiNW cycled in LP30 (black), FEC (red) and VC (blue) for 50 cycles, where the intense (truncated) peak at $74 \mathrm{ppm}$ is due to the DNP solvent tetrachloroethane (TCE); * = spinning sidebands. (b) Conventional, room temperature ${ }^{13} \mathrm{C} \mathrm{CP} \mathrm{NMR}$ of SiNW cycled in FEC $+5 \%{ }^{13} \mathrm{C}_{3} \mathrm{FEC}$ for 100 cycles (i) measured by ${ }^{1} \mathrm{H}-{ }^{13} \mathrm{C} \mathrm{CP}$, (ii) measured by ${ }^{13} \mathrm{C}$ direct excitation (DE) with a recycle delay of $60 \mathrm{~s}$ to extract quantitative information.

${ }^{13} \mathrm{C}$ NMR spectra were also recorded for SiNWs cycled with ${ }^{13} \mathrm{C}$-enriched electrolyte $\left(\mathrm{FEC}+5 \%{ }^{13} \mathrm{C}_{3} \mathrm{FEC}\right.$ after 100 cycles, abbreviated as ${ }^{13} \mathrm{C}_{3}$ FEC100) using room-temperature NMR techniques (Figure $3 \mathrm{~b}$ ). The ${ }^{1} \mathrm{H}_{-}{ }^{13} \mathrm{C} \mathrm{CP}$ NMR spectrum (Figure $3 \mathrm{~b}, \mathrm{i})$ of ${ }^{13} \mathrm{C}_{3} \mathrm{FEC} 100$ is comparable to the spectrum of SiNWs cycled in FEC for 50 cycles (FEC50) obtained using DNP NMR (Figure 3a). The striking resemblance between the spectra of FEC50 and ${ }^{13} \mathrm{C}_{3}$ FEC100 suggests that the chemical units of the organic SEI formed in FEC from the $50^{\text {th }}$ to the $100^{\text {th }}$ cycle are chemically similar, indicating that the chemical units of the polymeric SEI are stable during cycling at this point, though the SEI thickness may vary. Furthermore, although no quantitative comparisons of these spectra were performed, we did not see any significant alteration in the chemical species found in the SEI, following the preparation of the sample for the DNP experiment, although it is likely that some of the organic components may dissolve in the TCE solvent used for DNP experiments.

Quantitative information about the organic SEI in the ${ }^{13} \mathrm{C}_{3}$ FEC100 sample is obtained from direct excitation (DE) roomtemperature ${ }^{13} \mathrm{C}$ NMR spectra (Figure $3 \mathrm{~b}$, ii). The integrated intensities of the deconvoluted peaks are summarized in Table 2.
The organic species in the ${ }^{13} \mathrm{C}_{3} \mathrm{FEC} 100$ sample primarily consist of aliphatic moieties ( $41 \%$ of the total peak area) and PEOtype oligomers $(30 \%)$. Relatively small concentrations of alkyl carbonate $(11 \%)$, carboxylate $(4 \%)$ and lithium carbonate $(4 \%)$ species are also present in the SEI. The quantitative ${ }^{13} \mathrm{C}$ NMR spectrum suggests that the branching units (acetal carbons, $\mathbf{C}$ in Table 2) account for $8 \%$ of the total integral of the spectrum, indicating that the polymers are highly cross-linked. Peak $\mathbf{D}$ at $128 \mathrm{ppm}$ (Figure 3b, ii), which is attributed to alkene carbons, is also present in the deconvoluted spectrum and it is consistent with the DNP NMR spectra of FEC and VC samples (Figure $3 a)$. Note that such alkene species are also observed as soluble products in the cycled FEC and VC electrolytes (Figure S3). The unsaturated carbon units are likely the base units for polymerization. ${ }^{10,47}$

Table 2 Summary of the intensity and assignments of the peaks obtained by deconvolution of the ${ }^{13} \mathrm{C}$ direct excitation ssNMR spectrum of the ${ }^{13} C_{3}$ FEC sample.

\begin{tabular}{|lllll|}
\hline Label & $\begin{array}{l}\text { Peak cen- } \\
\text { tre } / \mathrm{ppm}\end{array}$ & $\begin{array}{l}\text { Peak } \\
\text { width/ } / \\
\mathrm{ppm}\end{array}$ & $\begin{array}{l}\text { Relative } \\
\text { Intensity } \\
(\%)\end{array}$ & Assignment \\
\hline
\end{tabular}




\begin{tabular}{|c|c|c|c|c|}
\hline A & 33.1 & 32.2 & 41 & $\mathrm{R}^{\mathrm{R}} \mathrm{H}_{2} \mathrm{R}^{\prime}$ \\
\hline $\mathrm{B}$ & 71.5 & 11.6 & 30 & $-\mathrm{CH}_{2} \underline{\mathbf{C}} \mathrm{H}_{2} \mathrm{O}-$ \\
\hline $\mathrm{C}$ & 100.7 & 11.4 & 8 & $\mathrm{R} \underline{\mathbf{C}} \mathrm{H}(\mathrm{OR})_{2}$ \\
\hline $\mathrm{D}$ & 129.7 & 15.9 & 2 & $\mathrm{R} \underline{\mathbf{C}} \mathrm{H}=\underline{\mathbf{C}} H^{\prime}{ }^{\prime}$ \\
\hline $\mathrm{E}$ & 155.3 & 7.3 & 11 & $\mathrm{RO} \underline{\mathbf{C O}}_{2} \mathrm{R}^{\prime}$ \\
\hline$F$ & 169.9 & 4.4 & 4 & $\mathrm{Li}_{2} \underline{\mathbf{C O}}_{3}$ \\
\hline G & 180.9 & 10.4 & 4 & $\mathrm{R} \underline{\mathrm{C}} \mathrm{O}_{2} \mathrm{Li}$ \\
\hline
\end{tabular}

on the ${ }^{13} \mathrm{C}_{3} \mathrm{FEC100}$ sample (Figure 4). In this spectrum, two spins with resonance frequencies $v_{l}$ and $v_{2}$ result in a correlation at $v_{1}+v_{2}$ in the indirect dimension of the 2D spectrum if they are coupled through space. Here, the spectrum mainly shows one-bond carbon-carbon correlations. Three broad peaks are observed in the ${ }^{13} \mathrm{C}$ spectrum with spectral ranges of $10-40 \mathrm{ppm}, 60-85 \mathrm{ppm}$ and $90-110 \mathrm{ppm}$, which are labeled $\mathbf{A}, \mathbf{B}$ and $\mathbf{C}$, respectively, consistent with the labeling scheme shown in Table 2. A is assigned to alkyl groups, $\mathbf{B}$ is attributed to PEO-type ethylene oxide carbons ${ }^{5}\left(-\mathrm{CH}_{2}-\underline{\mathrm{C}} \mathrm{H}_{2} \mathrm{O}-\right)$ in linear and branched moieties, and $\mathbf{C}$ mainly arises from an acetal car-

\section{Molecular fragments in the organic SEI}

To establish the connectivity between distinct chemical motifs observed in the organic SEI, we performed a 2D doublequantum single-quantum (DQ-SQ) ${ }^{13} \mathrm{C}$ homonuclear dipolar correlation experiment using POST-C7 with DNP enhancement

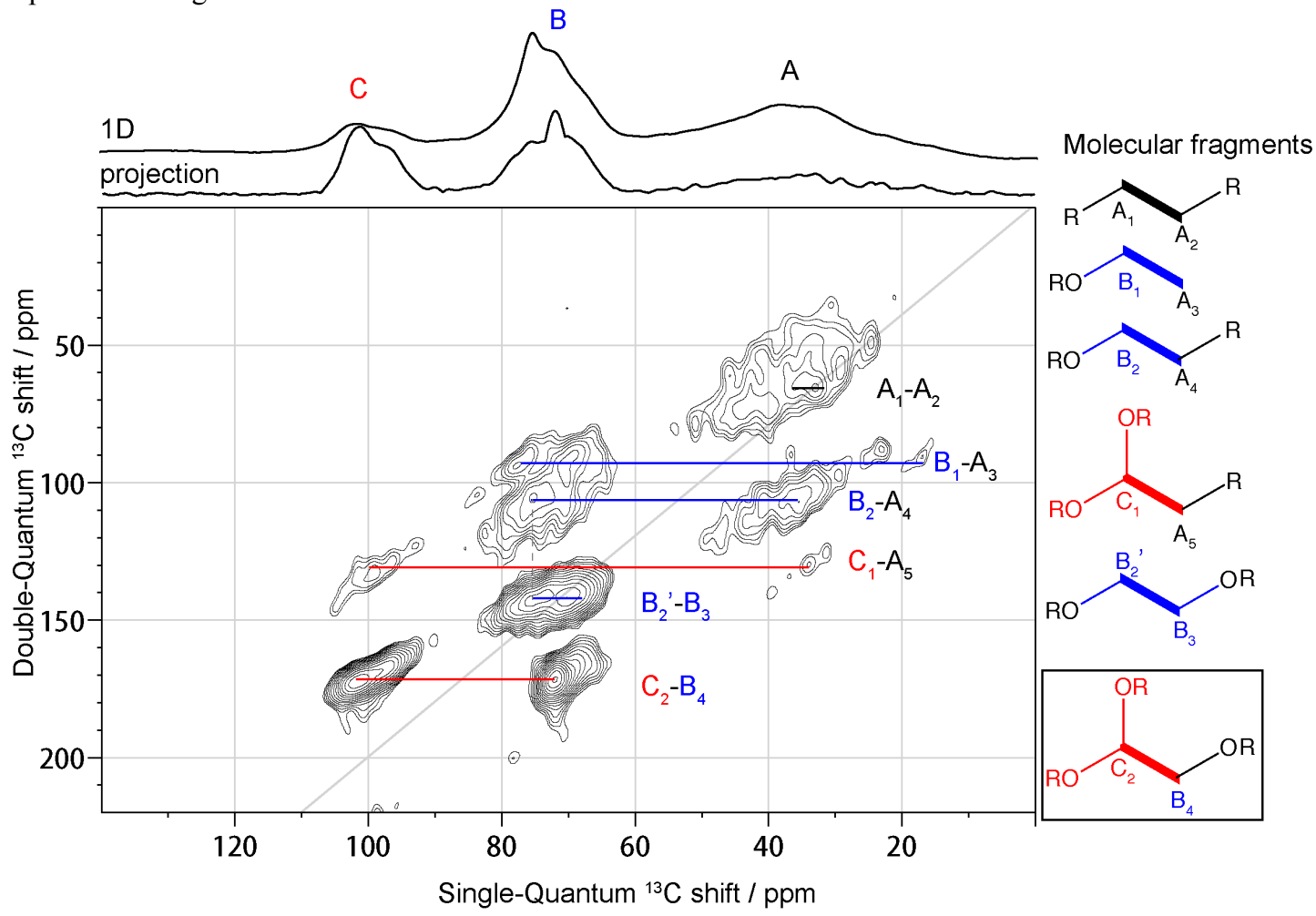

Figure 4 DNP enhanced 2D DQ-SQ ${ }^{13} \mathrm{C}-{ }^{13} \mathrm{C}$ POST-C7 dipolar correlation spectrum of SiNW cycled in FEC $+5 \%{ }^{13} \mathrm{C}_{3} \mathrm{FEC}$ for 100 cycles. $1 \mathrm{D}{ }^{1} \mathrm{H}-{ }^{13} \mathrm{C}$ CP NMR and the total projection in the SQ dimension are overlaid on top. The corresponding molecular fragments are listed on the right panel. The branching fragments are colored in red; the fragments containing ethylene oxide carbons are colored in blue and the alkyl chains in black. The spectrum is recorded at $105 \mathrm{~K}$. The MAS frequency and the number of scans is $8 \mathrm{kHz}$ and 384 , respectively. The spectrum is obtained in $\sim 9 \mathrm{~h}$ with a recycle delay of $2 \mathrm{~s}, 1.8 \mathrm{~ms}$ evolution time, and $2 \mathrm{~ms}$ POST-C7 mixing time.

Scheme 1 Possible molecular fragments observed in the FEC/VC decomposition products. The cyclic region is highlighted in yellow, the branching units are colored in red, ethylene oxide units in blue and alkyl chains in grey. A cross-linked cyclic acetal group is shown shaded in yellow. Carbons labeled with $\mathrm{A}-\mathrm{C}$ are consistent with the results from the $2 \mathrm{D}$ carbon correlation NMR experiment shown in Figure 4. The ${ }^{13} \mathrm{C}$ NMR shifts are derived from Figures $2 \mathrm{e}$ and $\mathrm{f}$. The relative concentrations of the different species vary between the SEIs formed with different electrolytes. 


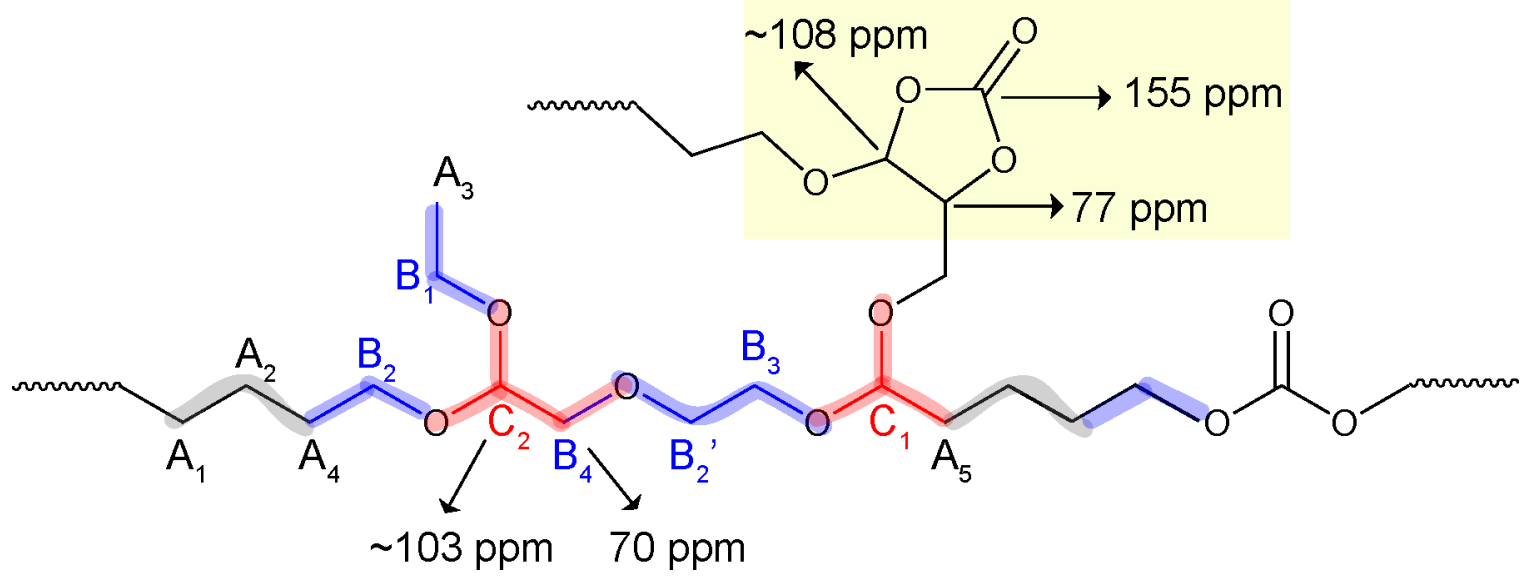

correlation observed is between $\mathbf{B}_{\mathbf{4}}$ and $\mathbf{C}_{\mathbf{2}}$, followed by $\mathbf{B}_{\mathbf{2}}$ ' and $\mathbf{B}_{\mathbf{3}}$. The $\mathbf{B}_{\mathbf{2}}$ '- $\mathbf{B}_{\mathbf{3}}$ correlation is assigned to connections between ethylene oxide fragments $\left(-\mathrm{O} \underline{\boldsymbol{C}} \mathrm{H}_{2} \underline{\boldsymbol{C}} \mathrm{H}_{2} \mathrm{O}-\right)$ that are found in PEO-type polymers. ${ }^{44}$ The strongest $\mathbf{B}_{4}-\mathbf{C}_{2}$ correlation indicates that acetal carbon $\mathbf{C}$ is directly bound to a PEO-type ethylene oxide carbon $\mathbf{B}$, which provides strong evidence that the acetal carbon $\mathbf{C}$ is, indeed, a branching unit in the PEO-type polymer. Note that $\mathbf{B}_{4}$ has a ${ }^{13} \mathrm{C}$ shift of $72 \mathrm{ppm}$ (see Table S4 for all the correlation peaks in Figure 4), which can be assigned

(a) ${ }^{1} \mathrm{H}^{29} \mathrm{Si}$ cross polarization

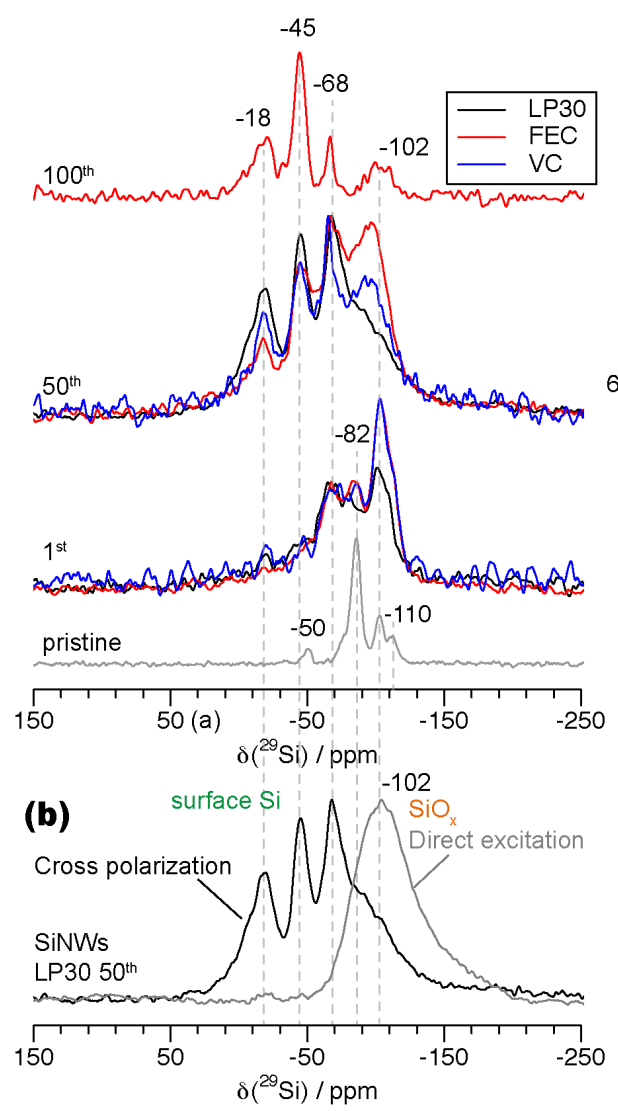

to a linear ethylene oxide (EO) carbon instead of a branched EO unit $\left(-\mathrm{CH}_{2} \underline{\mathrm{C}} \mathrm{HRO}-\text {, with }{ }^{13} \mathrm{C} \text { shift around } 77 \mathrm{ppm}\right)^{48}$. Moreover, the $\mathbf{B}_{4}-\mathbf{C}_{2}$ fragment ((RO) $)_{2} \underline{C}-\underline{C}-H_{2} \mathrm{OR}$ ') has the same connectivity as that of a soluble decomposition product we previously identified in the cycled LP30 + FEC electrolyte ${ }^{10}$ (the structure is highlighted in the box in Figure 4). In the presence of FEC, the $\mathbf{B}_{\mathbf{4}}-\mathbf{C}_{\mathbf{2}}$ branched molecular fragment is found in both the soluble degradation products and in the insoluble component; it

(c)

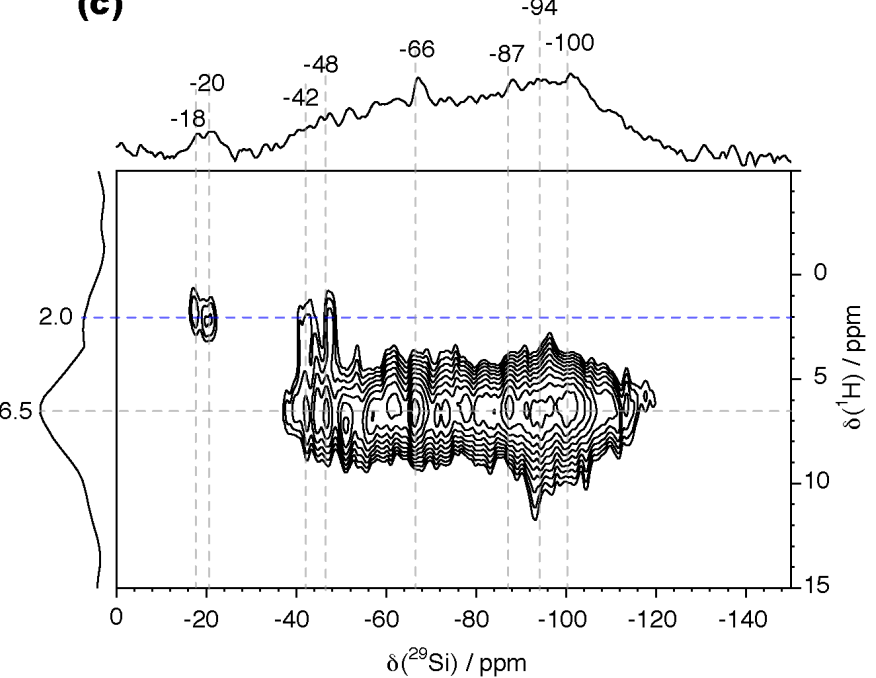

(d)

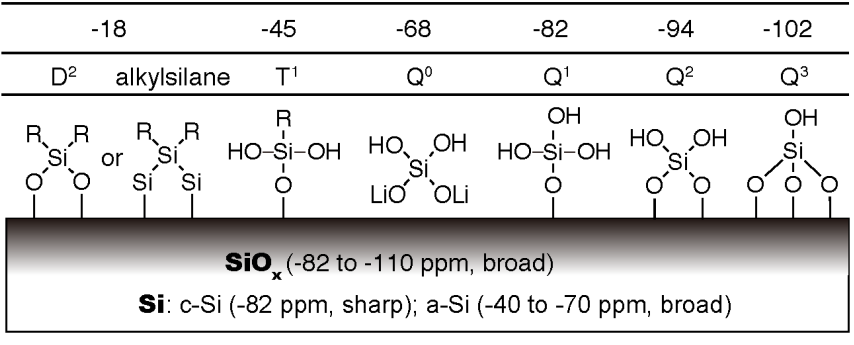

Figure $5{ }^{29} \mathrm{Si}$ NMR spectra of cycled Si using different techniques. (a) ${ }^{1} \mathrm{H}-{ }^{29} \mathrm{Si}$ CP DNP NMR of SiNWs after the first, 50 and 100 cycles; pristine silicon nanoparticles were measured by ${ }^{1} \mathrm{H}^{2}{ }^{29} \mathrm{Si} \mathrm{CP}$ NMR without DNP and its spectrum is included for comparison. (b) ${ }^{29} \mathrm{Si}$ DNP NMR using cross polarization (CP) and direct excitation (DE) on SiNWs cycled in LP30 for 50 cycles, with recycle delay of $3.5 \mathrm{~s}$ and $10 \mathrm{~s}$, respectively. The CP spectrum mainly shows proton-containing surface species, whereas the DE spectrum (grey in b) mainly contains signals from the outer $\mathrm{SiO}_{\mathrm{x}}$ shell on the SiNWs. (c) ${ }^{1} \mathrm{H}^{29}{ }^{2} \mathrm{Si}$ HETCOR of SiNWs cycled in FEC for 50 cycles with a 5 ms contact time and recycle 
delay of 3 s. (d) Cartoon showing possible Si surface structures and their corresponding chemical shifts; R denotes an alkyl group. The proposed structures are mainly based on the ${ }^{1} \mathrm{H}_{-}{ }^{29} \mathrm{Si}$ HETCOR result. ${ }^{29} \mathrm{Si}$ shifts of $\mathrm{SiO}_{\mathrm{x}}$ and $\mathrm{Si}$ species are summarized: crystalline silicon (c-Si) -81 ppm; amorphous silicon (a-Si) -40 to $-70 \mathrm{ppm}^{49}$.

appears to be a unique decomposition product from FEC that is absent in standard LP30 electrolyte.

Weaker A-B, A-A and A-C correlations are also observed, the latter being assigned to acetal carbons connected to aliphatic groups. Within the broad peak $\mathbf{A}$, the $\mathbf{A}_{3}$ environment with ${ }^{13} \mathrm{C}$ resonance at $18 \mathrm{ppm}$ is assigned to a terminal methyl group ($\left.\underline{\mathrm{C}} \mathrm{H}_{3}\right)^{5}$, while other A sites with ${ }^{13} \mathrm{C}$ shifts spanning from $30-40$ pm arise from other alkyl groups $\left(-\underline{C} \mathrm{H}_{2} \mathrm{R}, \underline{-\boldsymbol{C}} \mathrm{HR}_{2},-\underline{\boldsymbol{C}} \mathrm{R}_{3}\right)$. The $\mathbf{A}_{1}-\mathbf{A}_{2}$ correlations correspond to the connections within aliphatic carbon chains, while the $\mathbf{A}_{\mathbf{3}}-\mathbf{B}_{\mathbf{1}}$ and $\mathbf{A}_{\mathbf{4}}-\mathbf{B}_{\mathbf{2}}$ peaks correspond to PEO-type carbons being bound to aliphatic carbons.

Aliphatic carbons (A) are the major species in the organic SEI (Table 2), but its correlations to other peaks are weaker than the correlations for B-C and B-B in Figure 4. The aliphatic carbon chain with A-A correlation is less pronounced probably due to its formation pathway that involves more than one molecular fragment. Since only $5 \mathrm{vol} \%{ }^{13} \mathrm{C}_{3} \mathrm{FEC}$ is used in the electrolyte, the probability of finding a two ${ }^{13} \mathrm{C}$ labeled spin pairs in aliphatic chains is largely decreased.

A possible molecular fragment containing the correlations observed in Figure 4 is depicted in Scheme 1. The branching units are shaded in red, ethylene oxide chains in blue and alkyl carbons in grey. Characteristic ${ }^{13} \mathrm{C}$ NMR shifts observed in the cycled FEC/VC sample (Figure 2e and f) are also tentatively assigned in this structure. A cyclic acetal unit highlighted in yellow is also shown. The poly(VC) units are not illustrated in this Scheme since they appear to be present in lower concentrations in the FEC samples than in the VC samples. In part due to the low enrichment level $\left(5 \%{ }^{13} \mathrm{C}_{3} \mathrm{FEC}\right.$ in the electrolyte), and dipolar truncation effects, multiple-bond correlations were not obtained. Nevertheless, the various one-bond correlations detected in the system reflect the heterogeneous polymeric structure that is formed.

\section{Lithiated and Fluorinated Components in the SEI}

Inorganic Li salts are also observed by ${ }^{7} \mathrm{Li}$ and ${ }^{19} \mathrm{~F}$ ssNMR (Figure S6). For all FEC and VC samples, $\mathrm{LiF}$ is observed as a distinct peak at $-204 \mathrm{ppm}$ in the ${ }^{19} \mathrm{~F}$ NMR (Figure S6b), with FEC samples containing more $\mathrm{LiF}$ than $\mathrm{VC}$ samples. Apart from $\mathrm{LiF}$, residual $\mathrm{LiPF}_{6}$ salt $\left({ }^{19} \mathrm{~F}\right.$ NMR shift at $\left.-74 \mathrm{ppm}\right)$ is the dominant inorganic species in the SEI, as the samples were not rinsed. The products of $\mathrm{PF}_{6}{ }^{-}$anion hydrolysis, the $\mathrm{PO}_{2} \mathrm{~F}_{2}{ }^{-}\left({ }^{19} \mathrm{~F}\right.$ chemical shift $=-82 \mathrm{ppm})$ and $\mathrm{PO}_{3} \mathrm{~F}^{-}$anions $\left({ }^{19} \mathrm{~F}\right.$ doublet $=-97$ ppm) are observed, likely due to presence of trace amount of physiosorbed water on the separator and in the electrolyte. A small peak at -122 ppm was observed in the ${ }^{19} \mathrm{~F}$ ssNMR spectra of cycled SiNWs (Figure S6), which can be assigned to $\mathrm{SiO}_{\mathrm{x}} \mathrm{F}_{\mathrm{y}}$ species. ${ }^{6}$ However, this peak is not consistently observed, and it is attributed to the contamination from glass fiber separator.

No evidence of a fluorinated polymer is found in the both the ${ }^{19} \mathrm{~F}$ and ${ }^{13} \mathrm{C}$ ssNMR spectra, fluorinated polymers resonating between -100 to $-130 \mathrm{ppm}$ and 100 to $130 \mathrm{ppm}$ in ${ }^{19} \mathrm{~F}$ and ${ }^{13} \mathrm{C}$ ssNMR, respectively. The absence of a fluorinated polymer suggests that FEC defluorinates prior to further reduction/reaction. The result is consistent with our previous study ${ }^{10}$ and theoretical work from Balbuena's group. ${ }^{50}$

\section{The $\mathrm{SiO}_{x}-\mathrm{SEI}$ Interface}

Figure 5a shows the ${ }^{1} \mathrm{H}^{-29} \mathrm{Si} \mathrm{CP}$ NMR spectra of pristine $\mathrm{Si}$ nanoparticles (SiNPs) measured with conventional NMR and SiNWs after the first, 50 and 100 cycles in different electrolytes with DNP enhancement. The spectrum of pristine SiNPs is shown here for comparison since the SiNPs are expected to show similar surface species to the SiNWs. Moreover, SiNPs are available in larger quantities allowing us to collect a spectrum with improved signal-to-noise ratio. The spectrum of the pristine SiNPs mainly consists of sharp resonances from bulk crystalline $\mathrm{Si}(-82 \mathrm{ppm})^{51}$ and Q-site hydroxyl-terminated silicates $\left({ }^{29} \mathrm{Si}\right.$ resonances at $-102 \mathrm{ppm}$ for $\mathrm{Q}^{3}$ and $-112 \mathrm{ppm}$ for $\mathrm{Q}^{4}$, where $\mathrm{Q}^{\mathrm{n}}$ represents $(\mathrm{SiO})_{n} \underline{\mathbf{S i}}\left((\mathrm{OH})_{4-n} \text { environments }\right)^{52}$. The weak peak at $-50 \mathrm{ppm}$ is tentatively assigned to the amorphous Si component in the nanoparticles. ${ }^{49}$

After cycling, the Si surface changes dramatically and di- (D), tri- (T), substituted siloxanes are observed (Figure 5a). We excluded the formation of hydrogen terminated Si species because no dramatic intensity decrease was observed in the ${ }^{1} \mathrm{H}-{ }^{29} \mathrm{Si}$ dipolar dephasing experiment for all the resonances observed in the ${ }^{29} \mathrm{Si} \mathrm{NMR}$ spectra (Figure S11), indicating that there are no $\mathrm{Si}-\mathrm{H}$ bonds.

After the first cycle, a new resonance at approximately -68 ppm arises, which can be tentatively assigned either to $\mathrm{T}^{3}$ organosiloxane $\left((\mathrm{SiO})_{3} \underline{\mathrm{Si}} \mathrm{R} \text {, where } \mathrm{R} \text { is aliphatic carbons }\right)^{35}$ or to $\mathrm{Q}^{0}$ single (non-bridging) tetrahedral silicate (possibly with some charge-balancing $\mathrm{Li}^{+}$ions, $\mathrm{Li}_{n} \mathrm{H}_{4-n} \mathrm{SiO}_{4}$, where $\mathrm{n}=1$ to 3 ). The ${ }^{1} \mathrm{H}-{ }^{29} \mathrm{Si}$ HETCOR of the SiNWs cycled in FEC for 50 cycles (Figure 5c) shows that the ${ }^{29}$ Si resonance around $-66 \mathrm{ppm}$ is connected to hydroxyl group(s) with ${ }^{1} \mathrm{H}$ shift at $6.5 \mathrm{ppm}$, but shows no cross peaks with protons on alkyl carbons (with ${ }^{1} \mathrm{H}$ shift around $2.0 \mathrm{ppm}$ ), indicating that $\mathrm{Si}-\mathrm{C}(\mathrm{H})$ groups are not present. Therefore, the HETCOR data support the assignment of the -68 ppm ${ }^{29} \mathrm{Si}$ resonance to a $\mathrm{Q}^{0}$ silicate rather than $\mathrm{T}^{3}$ organosiloxane. By using various $\mathrm{CP}$ contact times, we find that the -68 ppm component has a fast $\mathrm{CP}$ build-up curve (Figure S10), confirming that this species is in close proximity to protons, suggesting that it is associated with a silanol group $\left(\mathrm{Li}_{n} \mathrm{H}_{4-n} \mathrm{SiO}_{4}\right)$ instead of a proton-free lithium orthosilicate $\left(\mathrm{Li}_{4} \mathrm{SiO}_{4}\right)$. Moreover, the intensity of the $-68 \mathrm{ppm}$ peak increased dramatically after air exposure and a second resonance at $-60 \mathrm{ppm}$ is observed (Figure S12). This may be due to the further hydrolysis of the $\mathrm{Li}_{n} \mathrm{H}_{4-n} \mathrm{SiO}_{4}$ and the other $\mathrm{Q}$ site species leading to the formation of a species that contains more abundant protons.

The $-82 \mathrm{ppm}$ peak in the SiNWs after the first cycle is attributed to $\mathrm{Q}^{1}$ sites $\left((\mathrm{SiO}) \underline{\mathbf{S i}}\left((\mathrm{OH})_{3}\right)\right.$ instead of crystalline $\mathrm{Si}$ $\left({ }^{29} \mathrm{Si} \text { shift at }-81 \text { to }-85 \mathrm{ppm}\right)^{53}$, as crystalline $\mathrm{Si}$ is completely amorphised during the first cycle based on the electrochemistry (amorphous Si has a very broad ${ }^{29} \mathrm{Si}$ shift around -40 to -70 $\mathrm{ppm}^{49}$ ). The HETCOR spectrum (Figure 5c) confirms that the $82 \mathrm{ppm}$ species is associated with a silanol proton $(6.5 \mathrm{ppm})^{35}$. Of note, the HETCOR spectrum reveals that although the $\mathrm{Q}^{1}$ ($82 \mathrm{ppm}$ ) resonance is more distinct, the broad silanol resonance spreads from -40 to $-120 \mathrm{ppm}$, the region around $-94 \mathrm{ppm}$ corresponding to a $\mathrm{Q}^{2}$ environment (i.e., $\left.\underline{\underline{S i}}(\mathrm{OSi})_{2}(\mathrm{OH})_{2}\right)$. The broad resonance reflects the distribution of local environments 
in the amorphous $\mathrm{Si}(\mathrm{OR})_{\mathrm{n}}\left(\mathrm{R}^{\prime}\right)_{(4-\mathrm{n})}(\mathrm{n}=0,1)$ network, (including $\mathrm{Si}-\mathrm{OH}$ vs. Si-O- $\mathrm{Li}^{+}$termination and $\mathrm{Si}-\mathrm{O}$ vs. SiR connectivity).

Two new ${ }^{29} \mathrm{Si}$ peaks at $-18 \mathrm{ppm}$ and $-45 \mathrm{ppm}$ become more pronounced in the SiNWs after 50 cycles. Based on its distinct chemical shift, the -18 ppm peak can be assigned to $\mathrm{D}^{2}$ $(\mathrm{SiO})_{2} \underline{\mathrm{SiR}}_{2}{ }^{54}$ or an alkylsilane $(\mathrm{Si})_{2} \underline{\mathrm{SiR}}_{2}{ }^{51}$ (Figure $5 \mathrm{~d}$ ). This assignment is confirmed by ${ }^{1} \mathrm{H}^{-29} \mathrm{Si}$ HETCOR (Figure 5c), where the ${ }^{29} \mathrm{Si}$ peak at $-18 \mathrm{ppm}$ is only correlated to the protons on alkyl species (2.0 ppm). For the -45 ppm Si peak, correlations to both the protons on alkyl carbons $(2.0 \mathrm{ppm})$ and hydroxide protons $(6.5 \mathrm{ppm})$ are observed in the ${ }^{1} \mathrm{H}_{-}{ }^{29} \mathrm{Si}$ HETCOR spectrum, thus the $-45 \mathrm{ppm}$ resonance can be ascribed to a $\mathrm{T}^{1}$ site $(\mathrm{SiO}) \underline{\mathrm{SiR}}(\mathrm{OH})_{2} \cdot{ }^{55} \mathrm{Such}$ organosiloxane species can be formed via the reduction of the hydroxyl groups on the surface forming a Si-C bond (possible reactions will be discussed later). A similar trend is observed in SiNWs after 100 cycles in ${ }^{13} \mathrm{C}_{3} \mathrm{FEC}$ electrolyte: the intensity of organosiloxane species with a ${ }^{29} \mathrm{Si}$ shift at $-45 \mathrm{ppm}$ increases further, while the relative intensity of the $\mathrm{Q}^{3}$ sites at $-102 \mathrm{ppm}$ significantly decreases. In general, we find that the hydroxyl terminated species on the Si surface are gradually converted to organosiloxanes as a function of cycling.

Figure 5 b compares the ${ }^{29} \mathrm{Si}$ NMR spectra obtained by cross polarization (CP) vs. direct excitation (DE) of SiNWs cycled in LP30 for 50 cycles. In the ${ }^{1} \mathrm{H} \rightarrow{ }^{29} \mathrm{Si} \mathrm{CP}$ experiment, polarization of ${ }^{29} \mathrm{Si}$ nuclei located near the surface is enhanced as there are few protons inside the bulk Si and CP transfers are only effective up to a few angstroms. In the DE experiment, any Si species (both protonated and non-protonated) close to DNP biradicals are enhanced with a penetration depth of $1-5 \mathrm{~nm} .{ }^{56}$ The broad peak around $-102 \mathrm{ppm}$ in the DE spectrum indicates that a wide range of environments are present, including $\mathrm{Q}^{3}$ site hydroxide terminated silicates and $\mathrm{SiO}_{\mathrm{x}}$ non-protonated species. Both the -18 and -45 ppm peaks are also observed but are much weaker. These results suggest that the organosiloxane species observed in the ${ }^{1} \mathrm{H}-{ }^{29} \mathrm{Si}$ CP DNP NMR spectra are at the extreme surface of the $\mathrm{SiO}_{\mathrm{x}}$ layer and only account for a small fraction of the oxide layer (1-5 nm) in the cycled $\mathrm{Si}$ anode.

Apart from the cycle number, the electrolyte solvents also affect the relative intensities of each Si component. Though CP DNP NMR is not absolutely quantitative, the intensity difference allows an estimation of the relative populations of different $\mathrm{Si}$ sites. All spectra are normalized by the $-68 \mathrm{ppm} \mathrm{Q}^{0}$ silicate peak (arbitrarily selected) to facilitate the comparison. After the first cycle, the relative intensity of $Q^{3}$ site $(-102 \mathrm{ppm})$ in the LP30 sample is much smaller than those in the FEC and VC samples. This indicates that native hydroxyl groups are converted to the silicate/organosiloxane sites, but that this conversion is more pronounced (or rapid) in LP30 than in pure FEC and $\mathrm{VC}$ electrolytes (i.e. more organosiloxanes and $\mathrm{Q}^{0}$ species are formed in LP30). In the $50^{\text {th }}$ cycle, the same trend is observed: the $\mathrm{Q}^{3}$ sites in LP30 are weaker compared to $\mathrm{VC}$ and FEC, with FEC still having the most intense $Q^{3}$ peak. The peak intensities of organosiloxanes (-18 ppm and $-45 \mathrm{ppm})$ are also slightly larger in the LP30 sample than in the FEC and VC samples. In short, the $\mathrm{SiO}_{\mathrm{x}}$ surface reduction is more pronounced in the LP30 than in FEC and VC electrolytes.

\section{DISCUSSION}

The SEI derived from pure FEC and VC electrolytes contains a large amount of branched or cross-linked PEO, which is similar to LP30 + 10 vol\% FEC, but different from the linear PEOtype polymer observed in the additive-free LP30 sample. ${ }^{5,6,10}$ In this study, the cross-linking units were found to be acetal carbons connected to PEO-type carbons, as confirmed by a ${ }^{13} \mathrm{C}-{ }^{13} \mathrm{C}$ homonuclear correlation NMR experiment (Figure 4). Across all samples, we find that the presence of the acetal carbon is consistently associated with improved capacity retention. Methoxide groups are also observed, which likely represent end (terminal) groups of the organic polymer. Of note, the hydroxyl groups in PEO-type solid polymer electrolytes have been chemically modified to form methoxide groups, which are expected to reduce the polymers' reactivity towards Li metal ${ }^{57}$ and potentially increase the chemical stability of the SEIs.

Cross-linked PEO can be formed following the reaction pathway described in our previous work. ${ }^{10}$ Briefly, FEC defluorinates forming an EC radical, which transforms to $\mathrm{VC}$ via hydrogen loss. Alternatively, the EC radical forms vinoxyl radical $\left(\mathrm{O}=\mathrm{CHCH}_{2} \bullet\right.$ or $\left.\bullet \mathrm{OCH}=\mathrm{CH}_{2}\right)$ with concurrent loss of $\mathrm{CO}_{2}$ (Scheme 1). VC can also be reduced to a radical anion ($\mathrm{OCH}=\mathrm{CH} \bullet$ ), which is stabilized by $\pi$ conjugation. The vinoxyl radical can react with an $\mathrm{sp}^{2}$-hybridized carbon, forming branched species containing acetal carbons, aldehyde and alkene terminations (see reference ${ }^{10}$, scheme 3 ), all of which are observed in our ${ }^{13} \mathrm{C}$ NMR experiments. In EC based electrolyte, no such branched species were observed. One possible explanation is that for $\mathrm{EC}$ ring-opening reduction dominates, and the reduced species (e.g. ${ }^{\circ} \mathrm{CH}_{2} \mathrm{CH}_{2} \mathrm{OCOO}^{-}$) cannot easily lose protons to form the vinoxyl radicals. Due to the lack of vinoxyl radicals and unsaturated carbons, no significant concentrations of branched polymers are formed in standard LP30 electrolyte.

\section{Scheme 2. Possible reduction reactions for FEC and VC based on $\operatorname{Ref}^{10,58}$.}

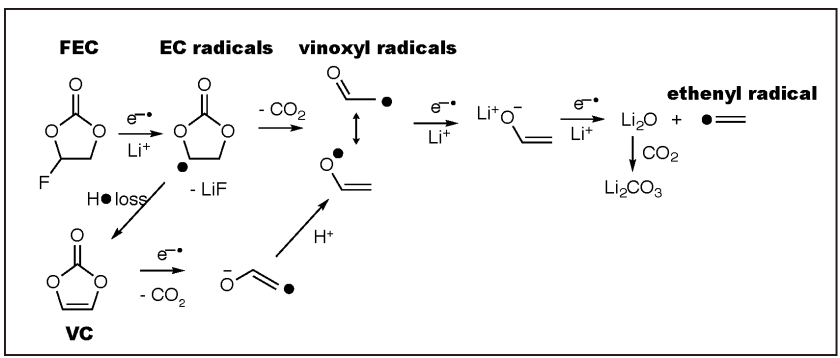

Apart from the cross-linked PEO, the SEIs formed from pure FEC and VC also contain a large amount of aliphatic carbons, which are absent in EC based sample. The large quantities of alkyl carbons in the FEC and VC samples are consistent with the oxygen-deficient species identified by Nakai et al. in the SEI formed on Si thin films in a FEC/DMC solvent. ${ }^{30}$ Based on XPS and ToF-SIMS results, the authors concluded that the oxygendeficient species is a polyene type polymer. Here, we observed that such oxygen-deficient polymers primarily contain alkyl chains instead of unsaturated carbons (with ${ }^{13} \mathrm{C}$ resonances around 120-140 ppm), although a small amount of alkenes are observed in pure FEC/VC electrolytes (Figure S3 in the SI). Oxygen deficient species can be formed by further reduction of vinoxyl radicals with the formation of $\mathrm{Li}_{2} \mathrm{O}$ (Scheme 2). The reduced species, such as ethenyl radicals ${ }^{58}$, can form dimers that subsequently polymerize, resulting in cross-linked aliphatic chains. Reactions with other radicals, including those formed on reductive ring-opening of the cyclic carbonate can also generate aliphatic groups; this mechanism is thought to be responsible for LEDC and LBDC formation. ${ }^{5}$ Though we have not observed the radicals, reduction reactions of this nature must occur 
as the aliphatic carbons account for $\sim 41 \%$ of the total carbon signal (Table 2). Fewer aliphatic carbons were observed in the EC/DMC system, presumably because the major reduction reactions do not involve the formation of ethylene radicals and/or require reactions involving radical (re)combination. ${ }^{44}$

${ }^{29} \mathrm{Si}$ DNP NMR reveals the bonding nature between the organic SEIs and Si surface. Organosiloxane species grow on the $\mathrm{Si}$ surface as a function of cycling. The formation of $\mathrm{Si}-\mathrm{C}$ bonds has previously been predicted by Balbuena and coworkers using DFT and $a b$ initio molecular dynamic simulations. ${ }^{50}$ Prior experimental evidence of a $\mathrm{Si}-\mathrm{C}$ species comes from XPS Si $2 p$ spectra, where the $\mathrm{SiO}_{2}$ peak shifts to lower binding energy after cycling (from $103 \mathrm{eV}$ to $101 \mathrm{eV}$ ), indicating that the $\mathrm{SiO}_{2}$ surface undergoes a reduction process during cycling. ${ }^{32-34}$ Our XPS Si 2p peaks of cycled SiNWs sample are broad: the 101 $\mathrm{eV}$ peak is not well resolved from the $103 \mathrm{eV}$ peak (see SI, Figure S4 for details). Nevertheless, the XPS data seems to suggest that the SEI in the VC sample is thicker than the FEC and LP30 samples after the same number of cycles.

Here, we utilized DNP and revealed detailed molecular structure concerning the Si surface. The formation of the organosiloxane is correlated with the reduction of the native oxide layer $\left(\mathrm{SiO}_{\mathrm{x}}\right)$ on $\mathrm{SiNWs}$. Reduction of the hydroxyl groups on $\mathrm{SiO}_{\mathrm{x}}$ surface likely leads to the formation of thermodynamically stable species (e.g. $\mathrm{LiOH}, \mathrm{Li}_{2} \mathrm{O}$ and $\mathrm{H}_{2}$ ) as well as andercoordinated silica radical $(\mathrm{SiO})_{2} \mathrm{Si}(\mathrm{OH}) \bullet$ (one possible reaction is illustrated in reaction 1). Note that the evolution of $\mathrm{H}_{2}$ gas from the reduction of FEC-based electrolyte has been reported by Jung et al. using on-line electrochemical mass spectrometry. ${ }^{58}$

$$
(\mathrm{SiO})_{2} \mathrm{Si}(\mathrm{OH})_{2}+2 \mathrm{Li}^{+}+2 \mathrm{e}^{-} \rightarrow(\mathrm{SiO})_{2} \mathrm{Si}(\mathrm{OH})^{\bullet}+\mathrm{Li}_{2} \mathrm{O}+\frac{1}{2} \mathrm{H}_{2}
$$

The under-coordinated silica species can react further with the solvent, forming $\mathrm{Si}-\mathrm{C}$ bonds as outlined by reactions 2,3 and 4. Reactions with radicals formed via direct transfer of electron from the Li-Si-O surface may also occur. ${ }^{50}$

$$
(\mathrm{SiO})_{2} \mathrm{Si}(\mathrm{OH})^{\bullet}+\mathrm{R}-\mathrm{H} \rightarrow(\mathrm{SiO})_{2} \mathrm{SiR}(\mathrm{OH})+\mathrm{H} \bullet
$$

$$
\begin{aligned}
& \text { or }(\mathrm{SiO})_{2} \mathrm{Si}(\mathrm{OH})^{\bullet}+\mathrm{EC} \rightarrow(\mathrm{SiO})_{2} \mathrm{Si}(\mathrm{OH})-\mathrm{CH}_{2} \mathrm{CH}_{2}-\mathrm{O}(\mathrm{C}=\mathrm{O}) \\
& \mathrm{O} \bullet
\end{aligned}
$$

$$
\begin{aligned}
& (\mathrm{SiO})_{2} \mathrm{Si}(\mathrm{OH})-\mathrm{CH}_{2} \mathrm{CH}_{2}-\mathrm{O}(\mathrm{C}=\mathrm{O}) \mathrm{O} \bullet \\
& (\mathrm{SiO})_{2} \mathrm{Si}(\mathrm{OH})-\mathrm{CH}_{2} \mathrm{CH}_{2}-\mathrm{O}^{-} \mathrm{Li}^{+}+\mathrm{CO}_{2}
\end{aligned}
$$

The $\mathrm{D}^{2}$ site (-18 ppm) observed in ${ }^{29} \mathrm{Si}$ NMR (Figure 5) can be formed via the reduction reactions proposed above, by substitution of two $-\mathrm{OH}$ groups in $(\mathrm{SiO})_{2} \mathrm{Si}(\mathrm{OH})_{2}$ with two $\mathrm{R}$ groups. The growth of the $D_{n}$ and $T_{n}$ species as a function of cycle number indicates a dynamic change of Si surface species and a sequential reduction process of the $\mathrm{SiO}_{\mathrm{x}}$ surface.
SiNWs cycled in LP30 electrolyte show more severe reduction of $\mathrm{SiO}_{\mathrm{x}}$ compared to those cycled in pure FEC or VC electrolytes. One possible origin for this difference may lie in the variation of the polymeric SEI structures. For example, the cross-linked polymer formed from FEC and VC may inhibit solvent permeation through the SEI and thus slow down the reaction between the solvents and the $\mathrm{SiO}_{\mathrm{x}}$ surface. Since the EC reduction mechanisms occur at lower voltages, i.e., EC is more stable, it may be that coupled reactions involving EC reduction and $\mathrm{Si}-\mathrm{C}$ bond formation play an important role in reducing the $\mathrm{SiO}_{\mathrm{x}}$ surface. Finally, the differences may also be related to the different changes in silicon morphologies on cycling EC vs. $\mathrm{FEC} / \mathrm{VC}$ electrolytes, leading to variations in the nature and quantities of exposed surfaces.

Calculations have shown that the lithiated silicon reacts with EC (and related molecules) by attack of the carbonate carbon, which does not result in the formation of a long-lived $\mathrm{Si}-\mathrm{C}$ bond. ${ }^{47}$ Instead breakdown products such as ethylene and $\mathrm{Li}_{2} \mathrm{CO}_{3}$, are formed. ${ }^{47}$ Thus, although the exposure of fresh (lithiated) silicon surfaces presumably promotes further electrolyte reactions, the fully lithiated silicides may not generate the stable Si-C species seen in this study, consistent with our suggestion that they arise from reactions of the silanol groups. Perez-Beltran et al. have shown by calculations that reduction of $\mathrm{Si}-\mathrm{OH}$ groups can lead to the formation of $\mathrm{Si}-\mathrm{H},{ }^{59}$ but we see no evidence for them in our NMR studies.

Since the organosiloxanes are formed on Si surfaces during electrochemical cycling, this suggests some stability of the Si$\mathrm{C}$ bonds in the reducing environment. SiNP uniformly coated with PEO-VC type polymer that contain such $\mathrm{Si}-\mathrm{C}$ bonds via click chemistry have been demonstrated to improve the cycle life of Si anodes, ${ }^{60}$ and the formation of such $\mathrm{Si}-\mathrm{C}$ species may also be relevant for strategies involving conformal coating $\mathrm{Si}$ with carbon and, in part, explain why carbon coatings help increase the $\mathrm{CE}$ and capacity retention. ${ }^{11,13}$ Additional information concerning the spatial arrangement of the organosiloxane layer on $\mathrm{Si}$ will be helpful to understand its passivating ability (e.g. is it a monolayer, or a core-shell structure, or simply formed in discrete regions on the surface) ${ }^{61}$ It is possible that such an interfacial layer maybe further tailored to achieve certain binding modes on the Si surface that might help to decrease the side reactions between $\mathrm{Si}$ and the electrolyte.

The previous XPS study of the SEI by Schroder et al. suggests that the Si surface can be passivated by forming Si-F species. ${ }^{31}$ In this work, no strong evidence to support the formation of SiF species was found in the ${ }^{29} \mathrm{Si}$ NMR and Si $2 p$ XPS spectra of cycled electrodes: these species have ${ }^{29} \mathrm{Si}$ NMR signals at around -105 to $-130 \mathrm{ppm}^{62}$ (Figure S9) and Si 2p XPS peaks around $106 \mathrm{eV}^{63}$ (Figure S4), but no obvious peaks were observed in either the XPS or NMR spectra. The $\mathrm{SiO}_{\mathrm{x}} \mathrm{F}_{\mathrm{y}}{ }^{19} \mathrm{~F}$ ssNMR resonance observed in some samples is attributed to the contamination of the sample with borosilicate separator. The results imply that while small amounts of Si-F species may be present on the electrode surface, they are not the dominant species, as they are below the detection limit of ${ }^{19} \mathrm{~F}$ NMR and XPS.

According to the well-known mosaic model ${ }^{3}$ and experimental evidence from XPS and TOF-SIMS ${ }^{31}$, the SEI nominally consists of two layers: the inner SEI close to the electrode surface that mainly comprises inorganic $\mathrm{Li}$ salts (such as $\mathrm{Li}_{2} \mathrm{O}, \mathrm{LiF}$ and $\mathrm{Li}_{2} \mathrm{CO}_{3}$ ), and the outer layer of the SEI which primarily contains the polymeric components. Our ${ }^{7} \mathrm{Li}$ and ${ }^{19} \mathrm{~F}$ ssNMR spectra (Figure S6) shows that $\mathrm{LiF}$, residual $\mathrm{LiPF}_{6}$ salt and $\mathrm{PF}_{6}$ 
breakdown products are clearly present in the cycled electrodes, decomposition of both the $\mathrm{PF}_{6}^{-}$anion and FEC contributing to the formation of $\mathrm{LiF}$. The presence of $\mathrm{Li}_{2} \mathrm{CO}_{3}$ is also confirmed by ${ }^{13} \mathrm{C}$ NMR as evidenced by the ${ }^{13} \mathrm{C}$ NMR resonance at 170 ppm (Figures 2 and 3). The role of inorganic species in the SEI is still unclear as they are observed in all the electrolyte formulations studied here and yet the $\mathrm{LiF}$ concentration, for example, does not correlate with improved electrochemistry. Factors such as in addition to chemical structure such as particle size, spatial distribution in the SEI, and interaction with the organic SEI may also be important. However, the important conclusion that we draw from the ${ }^{29} \mathrm{Si}$ DNP NMR and the multinuclear NMR studies is that the Si surface is not entirely covered by inorganic species but is partially bonded to the organic SEI.

Based on our initial chemical analysis, the difference in the electrochemical performance of LP30, FEC and VC can be explained at least in part by the differences in their polymeric SEIs. In EC-based electrolyte, linear PEO-type polymers form and some of the degradation products are more soluble than those derived from electrolyte containing FEC additives. ${ }^{10}$ The linear PEO-type polymer may not be able to accommodate the volume expansion of $\mathrm{Si}$ anode or have poorer $\mathrm{Li}$ ion conductivity than the branched PEO. ${ }^{64}$ Furthermore, continuous solvent decomposition on the Si surface leads to pore clogging of the electrode, which ultimately restricts the $\mathrm{Li}$ ion diffusion through the SEI. ${ }^{6}$

With the addition of FEC or VC, a heterogeneous polymer forms with specific functionalities: the cross-linked $\mathrm{PEO} /$ poly(VC) part can conduct Li ions and the aliphatic region may be electronic insulating and/or help prevent permeation of polar solvents. However, the cross-linked polymers formed in pure FEC and VC electrolytes do not form perfect barrier coatings as we still observe the continuous formation of organosiloxanes and Coulombic efficiencies of less than $99.5 \%$ in these systems.

The mechanical properties of cross-linked polymers formed in FEC and VC systems may also be different from their linear counterpart as they can be more elastic, thus helping to sustain the volume expansion of the $\mathrm{Si}$ anode and better protect the active material during cycling. ${ }^{65}$ In addition to the composition, the microstructure of the polymer (chain length, molecular weight, arrangement of repeating units in the backbone, etc.) can also influence the mechanical and ionic properties of the SEI, which is outside the scope of this current study.

To understand the heterogeneous organic SEI detected in the FEC and VC electrolyte better, knowledge from the field of solid polymer electrolytes (SPE) is of relevance, where new hybrid- and block-co-polymers show promising results for increasing ionic conductivity. ${ }^{66}$ For example, Khurana et al. reported a cross-linked SPE consisting of polyethylene and PEO with short chain polyethylene glycol plasticizer, which is chemically similar to the organic SEI we detected in the FEC/VC sample. Such SPE was found to exhibit high lithium conductivity $\left(>1.0 \times 10^{-4} \mathrm{~S} / \mathrm{cm}\right.$ at $\left.25^{\circ} \mathrm{C}\right)$ and was able to suppress the growth of Li dendrites. ${ }^{67}$ The relationship between the degree of cross-linking and $\mathrm{Li}$ ion conductivity was also explored by Thiam et al., ${ }^{68}$ who showed that the higher Li ion conductivity of PEO polymers $\left(1.0 \times 10^{-4} \mathrm{~S} / \mathrm{cm}\right.$ at $\left.30^{\circ} \mathrm{C}\right)$ can be obtained by controlling the cross-link density. Correlating the structure of the polymeric SEI with the electrochemical performance is key to fully understanding the SEI on alloy type anodes.
Finally, we return to the question of the Coulombic efficiencies, noting that while commercial cells use less electrolyte and thus the equilibrium between solid and liquid (dissolved) components will be different, the trends should still be similar. Despite the formation of more cross-linked polymers, and tethers to the $\mathrm{SiO}_{\mathrm{x}}$ matrix, the CEs (approx. 99.1\%) are still below that required for a commercial product. (Care must be taken in interpreting these numbers as parasitic reactions can occur on $\mathrm{Li}$ deposition meaning it is not necessarily $100 \%$ efficient, i.e., the total charge passed on charge may not correspond to $100 \% \mathrm{Li}$ deposition. However, on discharge, since the Li metal is in excess, this does not affect the additional capacities measured on Li stripping and lithiation of silicon. Thus, we believe that the $\mathrm{CE}$ does reflect the $\mathrm{CE}$ of the silicon anode.) It is clear that solvent still penetrates through the SEI and approaches the $\mathrm{SiO}_{x}$ surface sufficiently closely to allow electron tunneling and solvent reduction. Strategies that reduce solvent penetration are required to improve the SEI and we speculate that the success of cellulose binders ${ }^{69}$ lies in part due to the strong bonds to the $\mathrm{SiO}_{\mathrm{x}}$ surface and the fact that it does not swell in carbonate electrolytes.

\section{CONCLUSION}

This work has identified key chemical signatures on the surface and interphase of Si electrodes cycled in pure FEC and VC and a standard LP30 carbonate electrolyte with $1 \mathrm{M} \mathrm{LiPF}_{6}$. The SiNW electrodes cycled in FEC and VC electrolytes show better electrochemical performance than those cycled in standard LP30 based electrolytes. ${ }^{13} \mathrm{C}$ NMR experiments of both ${ }^{13} \mathrm{C}$ enriched and natural abundance electrolytes reveal that the organic electrochemical decomposition products of FEC and VC mainly consist of cross-linked PEO and alkyl chains with carbonate and carboxylate units forming $15 \%$ of the carbon content of the organic SEI.

For the FEC system, ${ }^{13} \mathrm{C}$-labelled electrolyte was used to perform the $2 \mathrm{D}{ }^{13} \mathrm{C}-{ }^{13} \mathrm{C}$ correlation experiment, which reveals key molecular fragments containing branched acetal carbons, confirming the formation of branched PEO type polymer (Figure 4).

The highly cross-linked PEO has three potentially positive implications for the stability of $\mathrm{Si}$ anodes. It may (i) reduce solvent penetration and swelling of the SEI helping to reduce further solvent reduction, (ii) accommodate the expansion and contraction of the silicon and (iii) may possibly have improved $\mathrm{Li}$ ion conductivities than linear PEO found in EC-based electrolytes ${ }^{68}$. Studies are currently underway to test these hypotheses.

The evolution of the Si surface structure is revealed by ${ }^{29} \mathrm{Si}$ DNP NMR. The hydroxyl terminated $\mathrm{SiO}_{x}$ is gradually reduced to form organosiloxane species containing $\mathrm{Si}-\mathrm{C}$ bonds, indicating that the $\mathrm{Si}$ surface is not entirely covered by inorganic $\mathrm{Li}$ salts but some $\mathrm{SiO}_{x}$ groups are also bonded to organic SEI components. We believe that the $\mathrm{Si}-\mathrm{C}$ bonds formed on cycling have intrinsic stability in the reducing environment. However, the presence of the $\mathrm{Si}-\mathrm{C}$ bond alone does not necessarily correlate to improved electrochemical performance. Likely it is both the chemical structures of the organic SEI and the uniformity of the SEI coverage on the active material that influence the cycle life of Si. Overall, this work has provided fundamental insight into the chemical species that form on cycling and result in increased Coulombic efficiencies and capacity retention in $\mathrm{Si}$ anodes for Li-ion batteries. 


\section{ASSOCIATED CONTENT}

\section{Supporting Information}

The Supporting Information is available free of charge on the ACS Publications website.

Further information about EIS, FTIR, XPS and ssNMR and experimental details are available. (PDF)

\section{AUTHOR INFORMATION}

\section{Corresponding Author \\ *cpg27@cam.ac.uk \\ Notes}

The authors declare no competing financial interest.

\section{ACKNOWLEDGEMENT}

The authors thank Prof. S. Hofmann for providing access to the CVD system to synthesize the SiNWs, YJ thanks Prof. L.M. Peng, Drs. W.B.Zhao, and D. Halat for useful discussion, and the Cambridge Trust and Chinese Scholarship Council for $\mathrm{PhD}$ funding. L.E.M acknowledges financial support through a FP7 Marie Cure International Incoming Fellowship. E.C.M acknowledges financial support through a H2020 Marie Sklodowska Cure Individual Fellowship. R.S.W. acknowledges a Research Fellowship from St. John's College, Cambridge and a H2020 Marie Sklodowska-Curie Individual Fellowship (Global) under grant ARTIST (No. 656870). E. J. acknowledges the Swedish Research Council for funding and SNIC for computer time. We acknowledge the Elettra Sincrotrone Trieste storage ring for provision of synchrotron radiation at the Escamicroscopy beamline and thank the Elettra staff, S. Emge and A. Gunnarsdóttir for support of the experiments. Financial support from the Engineering and Physical Sciences Research Council (U.K.) under the Supergen consortium and Amorpheous grant $(\mathrm{EP} / \mathrm{N} 001583 / 1)$ is acknowledged. The DNP experiments were performed at the DNP MAS NMR Facility at the University of Nottingham, with thanks to the EPSRC for funding of pilot studies (EP/L022524/1).

\section{REFERENCE:}

(1) Obrovac, M. N.; Chevrier, V. L. Chem. Rev. 2014, 114, 1144 1502.

(2) Xu, K. Chem. Rev. 2004, 104, 4303-4417.

(3) Peled, E.; Menkin, S. J. Electrochem. Soc. 2017, 164, A1703A1719.

(4) Aurbach, D.; Daroux, M. L.; Faguy, P. W.; Yeager, E. J. Electrochem. Soc. 1987, 134, 1611-1620.

(5) Michan, A. L.; Leskes, M.; Grey, C. P. Chem. Mater. 2015, 28 , 385-398.

(6) Michan, A. L.; Divitini, G.; Pell, A. J.; Leskes, M.; Ducati, C.; Grey, C. P. J. Am. Chem. Soc. 2016, 138, 7918-7931.

(7) Gireaud, L.; Grugeon, S.; Pilard, S.; Guenot, P.; Tarascon, J. M.; Laruelle, S. Anal. Chem. 2006, 78, 3688-3698.

(8) Aurbach, D.; Ein-Eli, Y.; Markovsky, B.; Zaban, A.; Luski, S.; Carmeli, Y.; Yamin, H. J. Electrochem. Soc. 1995, 142, 28822890.

(9) Xu, K.; Zhuang, G. R. V; Allen, J. L.; Lee, U.; Zhang, S. S.; Ross, P. N.; Jow, T. R. J. Phys. Chem. B 2006, 110, 7708-7719.

(10) Jin, Y.; Kneusels, N.-J. H.; Magusin, P. C. M. M.; Kim, G.; Castillo-Martinez, E.; Marbella, L. E.; Kerber, R. N.; Howe, D. J.; Paul, S.; Liu, T.; Grey, C. P. J. Am. Chem. Soc. 2017, 139, 14992-15004.

(11) Ng, S. H.; Wang, J.; Wexler, D.; Konstantinov, K.; Guo, Z. P.; Liu, H. K. Angew. Chemie - Int. Ed. 2006, 45, 6896-6899.

(12) Hu, Y. S.; Demir-Cakan, R.; Titirici, M. M.; Müller, J. O.; Schlögl, R.; Antonietti, M.; Maier, J. Angew. Chemie - Int. Ed. 2008, 47, 1645-1649.

(13) Liu, N.; Lu, Z.; Zhao, J.; Mcdowell, M. T.; Lee, H. W.; Zhao, W.;

Cui, Y. Nat. Nanotechnol. 2014, 9, 187-192. Chen, S.; Yang, Y. Electrochim. Acta 2015, 156, 11-19.

Han, X.; Chen, H.; Zhang, Z.; Huang, D.; Xu, J.; Li, C.; Chen, S.; Yang, Y. J. Mater. Chem. A 2016, 4, 17757-17763.

Chen, H.; Xiao, Y.; Wang, L.; Yang, Y. J. Power Sources 2011, 196, 6657-6662.

Han, X.; Chen, H.; Li, X.; Lai, S.; Xu, Y.; Li, C.; Chen, S.; Yang, Y. ACS Appl. Mater. Interfaces 2016, 8, 673-679.

Miyachi, M.; Yamamoto, H.; Kawai, H.; Ohta, T.; Shirakata, M. J. Electrochem. Soc. 2005, 152, A2089-A2091.

Haregewoin, A. M.; Wotango, A. S.; Hwang, B.-J. Energy Environ. Sci. Energy Environ. Sci 2016, 9, 1955-1988.

Zhao, W.; Ji, Y.; Zhang, Z.; Lin, M.; Wu, Z.; Zheng, X.; Li, Q.; Yang, Y. Curr. Opin. Electrochem. 2017, 6, 84-91.

Aurbach, D.; Gamolsky, K.; Markovsky, B.; Gofer, Y.; Schmidt, M.; Heider, U. Electrochim. Acta 2002, 47, 1423-1439.

Xu, K. Chem. Rev. 2014, 114, 11503-11618.

Cheng, X.-B.; Zhang, R.; Zhao, C.-Z.; Zhang, Q. Chem. Rev. 2017, 117, 10403-10473.

Xiao, Y.; Hao, D.; Chen, H.; Gong, Z.; Yang, Y. ACS Appl. Mater. Interfaces 2013, 5, 1681-1687.

Profatilova, I. A.; Stock, C.; Schmitz, A.; Passerini, S.; Winter, M. J. Power Sources 2013, 222, 140-149.

Nie, M.; Abraham, D. P.; Chen, Y.; Bose, A.; Lucht, B. L. J. Phys. Chem. C 2013, 117, 13403-13412.

Ota, H.; Sakata, Y.; Inoue, A.; Yamaguchi, S. J. Electrochem. Soc. 2004, 151, A1659.

El Ouatani, L.; Dedryvère, R.; Siret, C.; Biensan, P.; Reynaud, S.; Iratçabal, P.; Gonbeau, D. J. Electrochem. Soc. 2009, 156, A103A113.

Chen, L.; Wang, K.; Xie, X.; Xie, J. Electrochem. Solid-State Lett. 2006, 9, A512.

Nakai, H.; Kubota, T.; Kita, A.; Kawashima, A. J. Electrochem. Soc. 2011, 158, 798-801.

Schroder, K.; Alvarado, J.; Yersak, T. a.; Li, J.; Dudney, N.; Webb, L. J.; Meng, Y. S.; Stevenson, K. J. Chem. Mater. 2015, 27, 5531-5542.

Chan, C. K.; Ruffo, R.; Hong, S. S.; Huggins, R. a.; Cui, Y. J. Power Sources 2009, 189, 34-39.

Lindgren, F.; Xu, C.; Niedzicki, L.; Marcinek, M.; Gustafsson, T.; Björefors, F.; Edström, K.; Younesi, R. ACS Appl. Mater. Interfaces 2016, 8, 15758-15766.

Xu, C.; Lindgren, F.; Philippe, B.; Gorgoi, M.; Björefors, F.; Edström, K.; Gustafsson, T. Chem. Mater. 2015, 27, 2591-2599. Lelli, M.; Gajan, D.; Lesage, A.; Caporini, M. A.; Vitzthum, V.; Miéville, P.; Héroguel, F.; Rascón, F.; Roussey, A.; Thieuleux, C.; Boualleg, M.; Veyre, L.; Bodenhausen, G.; Copéret, C.; Emsley, L. J. Am. Chem. Soc. 2011, 133, 2104-2107.

Sangodkar, R. P.; Smith, B. J.; Gajan, D.; Rossini, A. J.; Roberts, L. R.; Funkhouser, G. P.; Lesage, A.; Emsley, L.; Chmelka, B. F. J. Am. Chem. Soc. 2015, 137, 8096-8112.

Berruyer, P.; Lelli, M.; Conley, M. P.; Silverio, D. L.; Widdifield, C. M.; Siddiqi, G.; Gajan, D.; Lesage, A.; Copéret, C.; Emsley, L. J. Am. Chem. Soc. 2017, 139, 849-855.

Ogata, K.; Salager, E.; Kerr, C. J.; Fraser, a E.; Ducati, C.; Morris, a J.; Hofmann, S.; Grey, C. P. Nat. Commun. 2014, 5, 3217.

Fung, B. M.; Khitrin, A. K.; Ermolaev, K. J. Magn. Reson. 2000, $101,97-101$.

Metz, G.; Wu, X. L.; Smith, S. O. Journal of Magnetic Resonance. 1994, 110, 219-227.

Thakur, R. S.; Kurur, N. D.; Madhu, P. K. Chem. Phys. Lett. 2006, $426,459-463$.

Hohwy, M.; Jakobsen, H. J.; Edén, M.; Levitt, M. H.; Nielsen, N. C. J. Chem. Phys. 1998, 108, 2686-2694.

Leifer, N.; Smart, M. C.; Prakash, G. K. S.; Gonzalez, L.; Sanchez, L.; Smith, K. A.; Bhalla, P.; Grey, C. P.; Greenbaum, S. G. J. Electrochem. Soc. 2011, 158, A471-A480.

Michan, A. L.; Parimalam, B. S.; Leskes, M.; Kerber, R. N.; Yoon, T.; Grey, C. P.; Lucht, B. L. Chem. Mater. 2016, 28, 81498159.

Etacheri, V.; Haik, O.; Goffer, Y.; Roberts, G. a.; Stefan, I. C.; Fasching, R.; Aurbach, D. Langmuir 2012, 28, 965-976.

Leskes, M.; Kim, G.; Liu, T.; Michan, A. L.; Aussenac, F.; 
Dorffer, P.; Paul, S.; Grey, C. P. J. Phys. Chem. Lett. 2017, 8, 1078-1085.

(47) Soto, F. A.; Ma, Y.; Martinez De La Hoz, J. M.; Seminario, J. M.; Balbuena, P. B. Chem. Mater. 2015, 27, 7990-8000.

(48) Ichikawa, K.; Dickinson, L. C.; MacKnight, W. J.; Watanabe, M. Polym. J. 1997, 29, 429-433.

(49) Shao, W.-L.; Shinar, J.; Gerstein, B. C.; Li, F.; Lannin, J. S. Phys. Rev. B 1990, 41, 9491-9494.

(50) Martínez de la Hoz, J. M.; Balbuena, P. B. Phys. Chem. Chem. Phys. 2014, 16, 17091.

(51) Lee, D.; Kaushik, M.; Coustel, R.; Chenavier, Y.; Chanal, M.; Bardet, M.; Dubois, L.; Okuno, H.; Rochat, N.; Duclairoir, F.; Mouesca, J. M.; De Paëpe, G. Chem. A Eur. J. 2015, 21, 1604716058.

(52) Lippmaa, E.; Magi, M.; Satnoson, A.; Engelhardt, G.; Grimmer, A.-R. J. Am. Chem. Soc. 1980, 5, 4889-4893.

(53) Giuliani, J. R.; Harley, S. J.; Carter, R. S.; Power, P. P.; Augustine, M. P. Solid State Nucl. Magn. Reson. 2007, 32, 1-10.

(54) Glaser, R. H.; Wilkes, G. L.; Bronnimann, C. E. J. Non. Cryst. Solids 1989, 113, 73-87.

(55) Mabboux, P.-Y.; Gleason, K. K. J. Electrochem. Soc. 2005, 1, 7 13.

(56) Lafon, O.; Rosay, M.; Aussenac, F.; Lu, X.; Trébosc, J.; Cristini, O.; Kinowski, C.; Touati, N.; Vezin, H.; Amoureux, J. P. Angew. Chemie - Int. Ed. 2011, 50, 8367-8370.

(57) Kelly, I. E.; Owen, J. R.; Steele, B. C. H. J. Power Sources 1985, 14, 13-21.

(58) Jung, R.; Metzger, M.; Haering, D.; Solchenbach, S.; Marino, C.; Tsiouvaras, N.; Stinner, C.; Gasteiger, H. A. J. Electrochem. Soc.
2016, 163, 1705-1716.

(59) Perez-Beltran, S.; Ramírez-Caballero, G. E.; Balbuena, P. B. J. Phys. Chem. C 2015, 119, 16424-16431.

(60) Gao, Y.; Yi, R.; Li, Y. C.; Song, J.; Chen, S.; Huang, Q.; Mallouk, T. E.; Wang, D. J. Am. Chem. Soc. 2017, 139, 17359-17367.

(61) Lee, D.; Monin, G.; Duong, N. T.; Lopez, I. Z.; Bardet, M.; Mareau, V.; Gonon, L.; Gaël De Paëpe. J. Am. Chem. Soc. 2014 136, 13781-13788

(62) Hoffner, F. M.; Delmotte, L.; Kessler, H. Zeolites 1993, 13, 60 63.

(63) Chan, C. K.; Ruffo, R.; Hong, S. S.; Cui, Y. J. Power Sources 2009, 189, 1132-1140.

(64) Watanabe, M.; Endo, T.; Nishimoto, A.; Miura, K.; Yanagida, M. J. Power Sources 1999, 81-82, 786-789.

(65) Dargel, V.; Shpigel, N.; Sigalov, S.; Nayak, P.; Levi, M. D.; Daikhin, L.; Aurbach, D. Nat. Commun. 2017, 8, 1389.

(66) Golodnitsky, D.; Strauss, E.; Peled, E.; Greenbaum, S. J. Electrochem. Soc. 2015, 162, A2551-A2566.

(67) Khurana, R.; Schaefer, J. L.; Archer, L. A.; Coates, G. W. J. Am. Chem. Soc. 2014, 136, 7395-7402.

(68) Thiam, A.; Antonelli, C.; Iojoiu, C.; Alloin, F.; Sanchez, J. Y. Electrochim. Acta 2017, 240, 307-315.

(69) Kovalenko, I.; Zdyrko, B.; Magasinski, A.; Hertzberg, B.; Milicev, Z.; Burtovyy, R.; Luzinov, I.; Yushin, G. Science. 2011, $334,75-79$. 


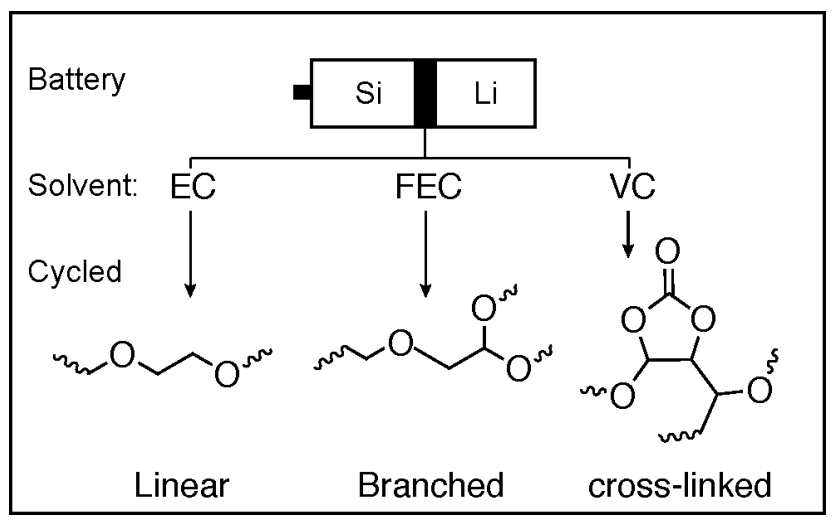

